\title{
Deciphering Phenotypic Diversity of Ralstonia solanacearum Strains Pathogenic to Potato
}

\author{
G. Cellier and P. Prior
}

First and second authors: CIRAD UMR Peuplements Végétaux et Bioagresseurs en Milieu Tropical, CIRAD-Université de la Réunion, Pôle de Protection des Plantes, 7, chemin de l'Irat, 97410 Saint Pierre, La Réunion, France; first author: AgroParisTech, ENGREF, 19 avenue du Maine, Paris F-75732, France; and second author: INRA, Département Santé des Plantes et Environnement. Accepted for publication 20 July 2010.

\begin{abstract}
Cellier, G., and Prior, P. 2010. Deciphering phenotypic diversity of Ralstonia solanacearum strains pathogenic to potato. Phytopathology 100:1250-1261.

Based on the phylotype classification, we questioned how genetically and phenotypically diverse strains of Ralstonia solanacearum pathogenic to potato may be. We studied 129 European and Mediterranean strains along with 57 reference strains known to cover genetic diversity in this species. Phylogeny analysis was done on endoglucanase gene sequences. Pathogenicity to potato, tomato, and eggplant was established at 24 to $30^{\circ} \mathrm{C}$ and 15 to $24^{\circ} \mathrm{C}$, whereas tests on banana were conducted at 24 to $30^{\circ} \mathrm{C}$. The ability to cause wilt on species of Solanaceae was shared by

phylotype IIB-27 established latent infections in banana, and Moko disease-causing phylotypes IIA-6, IIB-3, and IIB-4 were virulent to susceptible potato and tomato, addressing the question of host adaptation mechanisms, which may have undergone a similar bottleneck evolution. Cold-tolerance ability is only shared on species of Solanaceae among brown rot phylotype IIB-1, which gathered the majority of European and Mediterranean strains. We surveyed strain LNPV24.25 as the first report of an emerging phylotype IIB-4NPB strain in France. These findings showed that pathogenicity traits of genetically identified strains still need to be understood, especially in the perspective of post-genomics comparative analysis, to understand bacterial speciation in the $R$. solanacearum species complex.
\end{abstract} strains in all four phylotypes. Brown rot phylotypes IIB-1 and IIB-2 and
Ralstonia solanacearum is a soilborne plant-pathogenic $\beta$ proteobacterium with a wide host range and geographic distribution (17). Plants in at least 54 botanical families are affected in tropical and subtropical midland regions of the world (17-19). Strains within the species are heterogeneous and form part of a species complex (10). Bacterial wilt (BW) caused by $R$. solanacearum (Smith) (42) and recent introduction of brown rot strains in 14 of 27 Europe member states where outbreaks of brown rot have been reported, including The Netherlands, England, Belgium, and France $(9,14,20)$, pose a serious threat to most cash and subsistence crops in the family Solanaceae, especially potato, tomato, sweet pepper, and tobacco. Major economic losses (9) have led to the status of the pathogen as an A2-listed EPPO quarantine pest (http://www.eppo.org/QUARANTINE/listA2.htm) in Europe and the bacterium being considered as a bioterrorism select agent by relevant authorities in the United States (22).

The phylogeny-based classification of the $R$. solanacearum species complex established on the partial endoglucanase $(e g l)$ gene sequence was reported as a good indicator of relationships between strains (10-12) and it was shown to be congruent with organismal phylogeny based on pangenomic DNA microarray hybridization (16). Brown rot strains are clustered into phylotype IIB sequevar 1 (IIB-1) and phylotype IIB sequevar 2 (IIB-2), historically known as race 3 biovar 2 (R3bv2), and were first described as potato and tomato pathogenic but weakly virulent on other Solanaceae spp. (4). This group also presented a high clonal trend, especially for members which were isolated under tem-

Corresponding author: P. Prior; E-mail address: philippe.prior@cirad.fr

* The $\boldsymbol{e}$-Xtra logo stands for "electronic extra" and indicates that the online version contains a supplemental table.

doi:10.1094/PHYTO-02-10-0059

(c) 2010 The American Phytopathological Society perate climate $(17,20,36,38)$, showed different aggressiveness on Solanaceae spp. (37), and were able to trigger wilt even at cold temperatures (25).

Among the wide phylogenetic classification of $R$. solanacearum, major trends of pathogenicity were described and little is known about the exact virulence and aggressiveness of these strains. $R$. solanacearum strains which cluster into phylotype I encompassed a majority of lowland (tropical) strains with a wide host range. Within phylotype II, highland and cold-tolerant potato brown rot strains (2) belong to phylotype IIB-1 and IIB-2 (10), while many other lowland strains (formerly R1bv2T) are also able to cause wilt on Solanaceae spp., including potato (17). Phylotype IIB encompasses two distinctive clusters of banana Moko disease-causing strains (formerly R2bv1): sequevar 3 (IIB-3) and sequevar 4 (IIB-4). Recently, a new variant of $R$. solanacearum, that is pathogenic to the Solanaceae family but not pathogenic to banana (IIB-4NPB), has been recognized and also clusters into phylotype IIB-4 $(11,40)$. Two additional clusters-namely, sequevar 6 and sequevar 24-containing Moko disease-causing strains have been assigned to phylotype IIA. Phylotype IIA contains strains that generally have a broad host range and are primarily isolated from tropical regions (formerly R1bv1). African strains in the relatively newly described phylotype III have been reported to share some pathogenicity traits with brown rot strains, including pathogenicity to potato in the highland of West Cameroon (24). Although phylogenetically indistinguishable, strains clustered into the Indonesian phylotype IV-10 are represented by two distinct species adapted to different hosts: $R$. solanacearum strains pathogenic to both potato and tomato and the blood disease bacterium (BDB) that causes wilt only on banana (11). Closely related to phylotype IV-10, phylotype IV-9 strains are causal agents of the Sumatra disease of cloves, a bacterium transmitted by the tube-building cercopoids Hindola fulva in Sumatra and $H$. striata in Java (8). 
Many plant pathogen genomes are now available and many more are being sequenced, including members of the $R$. solanacearum species complex (https://www.genoscope.cns.fr/agc/ microscope/about/collabprojects.php?P_id=67). It is generally expected that mining genomic data will lead to major discoveries about the subtle interactions that occur between plants and pathogens, as recently reviewed by Alfano (1). Nevertheless, the $R$. solanacearum species complex encompasses an unusually large number of phenotypically and genetically diverse strains, and it has become obvious that any post-genomic initiative to decipher host specialization should primarily aim at unraveling diversity in phenotypes, with special attention to pathogenicity of strains. Using the phylotyping scheme and related diagnostic tools as a framework, we hypothesized that the genetic and pathogenic diversity of strains originating from Europe and the Mediterranean is much greater than expected. We focused on cold- tolerant potato brown rot strains of phylotype IIB-1, a major lineage of strains that is phylogenetically closely related to lineages containing banana Moko disease-causing strains. Within phylotype II, which encompasses the widest genetic diversity within the $R$. solanacearum species complex, both the brown rot and Moko disease-causing lineages are reported to be epidemiologically adapted to a particular host. That said, in this postgenomic data-mining era, the purpose of this study was to revisit and identify virulence patterns of these phenotypically divergent but genotypically similar $R$. solanacearum species complex strains.

\section{MATERIALS AND METHODS}

Bacterial strains. A set of $210 R$. solanacearum strains was obtained and 42 strains were selected (Table 1) to be part of the

TABLE 1. Strains of Ralstonia solanacearum used in the phylogenetic study based on sequence variations of partial endoglucanase (egl) gene

\begin{tabular}{|c|c|c|c|c|c|}
\hline \multirow[b]{2}{*}{ Strain $^{\mathrm{a}}$} & \multirow[b]{2}{*}{ RUN $^{\mathrm{b}}$} & \multirow[b]{2}{*}{ Origin, host } & \multicolumn{2}{|c|}{ Phylotype } & \multirow[b]{2}{*}{ GenBank $^{\mathrm{e}}$} \\
\hline & & & $\mathrm{PCR}^{\mathrm{c}}$ & $e g l^{\mathrm{d}}$ & \\
\hline GMI8044 & 585 & Grenada, banana & IIA-6 & IIA-6 & GU295013 \\
\hline RUN394 & 394 & Grenada, banana Bluggoe & IIA-6 & IIA-6 & GU295048 \\
\hline CFBP4822 & 646 & Finland, tomato & II & IIA-7 & GU294993 \\
\hline JS927 & 909 & Porto Rico, tomato & II & IIA-7 & GU295027 \\
\hline JS967 & 911 & Kenya, potato & II & IIA-7 & GU295028 \\
\hline CFBP4613 & 896 & Brazil, potato & II & IIA-28 & GU294982 \\
\hline PD1100 & 622 & Egypt, potato & II & IIA-35 & GU295043 \\
\hline CFBP3105 & 685 & Peru, potato & II & IIA-39 & GU294940 \\
\hline CFBP3858 & 689 & Netherlands, potato & II & IIB-1 & AF295259 \\
\hline CFBP3870 & 691 & South Africa, potato & II & IIB-1 & GU294949 \\
\hline CFBP4787 & 633 & Portugal, potato & II & IIB-1 & GU294986 \\
\hline CMR34 & 147 & Cameroon, tomato & II & IIB-1 & EF439750 \\
\hline JT516 & 160 & Reunion, potato & II & IIB-1 & AF295258 \\
\hline LNPV28.23 & 654 & Reunion, potato & II & IIB-1 & GU294927 \\
\hline PSS525 & 256 & Taiwan, potato & II & IIB-1 & EU407303 \\
\hline CFBP1410 & 461 & Colombia, banana plantain & II & IIB-2 & GU294936 \\
\hline CFBP3879 & 628 & Colombia, potato & II & IIB-2 & GU294954 \\
\hline CFBP1416 & 459 & Costa Rica, banana plantain & II & IIB-3 & GU294937 \\
\hline CIP417 & 264 & Philippines, banana & IIB-3 & IIB-3 & GU295004 \\
\hline CIP418 & 265 & Indonesia, peanut & IIB-3 & IIB-3 & GU295005 \\
\hline UW28 & 1366 & Cyprus, potato & IIB-3 & IIB-3 & GU295054 \\
\hline UW9 & 914 & Costa Rica, Heliconia sp. & IIB-3 & IIB-3 & AF295257 \\
\hline CFBP1184 & 908 & Honduras, Musa sp. & IIB-4 & IIB-4 & GU294935 \\
\hline LNPV31.10 & 662 & French Guiana, Musa sp. & IIB-4 & IIB-4 & GU294928 \\
\hline LNPV32.36 & 665 & French Guiana, Musa sp. & IIB-4 & IIB-4 & GU294931 \\
\hline LNPV32.37 & 666 & French Guiana, banana plantain & IIB-4 & IIB-4 & GU294932 \\
\hline LNPV32.40 & 668 & French Guiana, Musa sp. & IIB-4 & IIB-4 & GU294933 \\
\hline UW160 & 588 & Peru, banana plantain & IIB-4 & IIB-4 & GU295051 \\
\hline UW162 & 453 & Peru, banana plantain & IIB-4 & IIB-4 & AF295256 \\
\hline UW170 & 262 & Colombia, Heliconia sp. & IIB-4 & IIB-4 & DQ011550 \\
\hline IBSBF2001 & 981 & Brazil, tomato & II & IIB-25 & GU295017 \\
\hline UQRS607 & 1340 & Iran, potato & II & IIB-25 & GU295050 \\
\hline CFBP6778 & 289 & Martinique, tomato & IIB-4NPB & IIB-4 & EF371851 \\
\hline CFBP6797 & 277 & Martinique, American nightshade & IIB-4NPB & IIB-4 & EF371855 \\
\hline IBSBF1503 & 302 & Brazil, cucumber & IIB-4NPB & IIB-4 & EF371868 \\
\hline JY200 & 280 & Martinique, anthurium & IIB-4NPB & IIB-4 & EF371857 \\
\hline LNPV24.25 & 651 & France, tomato & IIB-4NPB & IIB-4 & GU295039 \\
\hline RUN432 & 432 & French Guiana, water (irrigation) & IIB-4NPB & IIB-4 & GU294926 \\
\hline CMR20 & 137 & Cameroon, tomato & III & III-29 & GU295006 \\
\hline MAFF301552 & 70 & Japan, tomato & IV & IV-8 & GU295042 \\
\hline CFBP6727 & 702 & Indonesia, potato & IV & IV-10 & GU294995 \\
\hline CFBP6728 & 703 & Indonesia, potato & IV & IV-10 & GU294996 \\
\hline \multicolumn{6}{|c|}{ Reference strains } \\
\hline $\mathrm{R} 288$ & 90 & China, mulberry & I & $\mathrm{I}-12$ & GQ907153 \\
\hline CFBP7058 & 215 & Cameroon, huckleberry & I & $\mathrm{I}-13$ & EF439740 \\
\hline PSS81 & 258 & Taiwan, tomato & $\mathrm{I}$ & $\mathrm{I}-14$ & FJ561066 \\
\hline \multirow[t]{2}{*}{ PSS4 } & 157 & Taiwan, tomato & I & $\mathrm{I}-15$ & EU407264 \\
\hline & & & & & (continued on next page) \\
\hline
\end{tabular}


phylogenetic tree from different bacterial collections maintained at Centre de coopération Internationale en Recherche Agronomique pour le Développement (Saint Pierre, Reunion Island; Le Lamentin, Martinique, French West Indies), Laboratoire National de la Protection des Végétaux (Angers, France), Institut National de la Recherche Agronomique (Rennes, France), University of Queensland (Brisbane, Australia), and Collection Française de Bactéries Phytopathogènes (Angers, France). Strains used in this study were isolated from BW field outbreaks or following interception from quarantined material by national plant health inspection services in Europe and the Mediterranean (EuMr). Collected strains were purified (i) onto modified Granada and Sequeira semiselective solid medium $(13,27)$ and (ii) on Kelman's triphenyltetrazolium chloride (TZC-Kelman's) solid medium complemented with $0.5 \mathrm{~g}$ of yeast extract (21). Cultures were streaked on plates and incubated for $48 \mathrm{~h}$ at $28^{\circ} \mathrm{C}$, and a single characteristic $R$. solanacearum colony for each strain was harvested and stored at $-80^{\circ} \mathrm{C}$ on beads (Pro-Lab Diagnostics, Microbank, Toronto).

Multiplex polymerase chain reactions for strains identification. The multiplex polymerase chain reaction (Pmx-PCR), developed by Fegan and Prior (10), was used to confirm that strains were $R$. solanacearum and to identify the phylotype to which they belonged. Strains from phylotype II originating from EuMr were further characterized by using a second specific multiplex PCR for Moko disease-causing strains (Mmx-PCR) in the Musa phylotypes IIA sequevar 6 (IIA-6), IIB-3, IIB-4, or IIB4NPB $(29,40)$.

Sequencing of partial $\boldsymbol{e g l}$ gene and phylogeny. Sequences of egl $(n=186)$ (Table 1) were either retrieved from GenBank $(n=$ $57)$ or determined in this study $(n=129)$ from a selection of strains isolated or intercepted in EuMr with a special care to strains isolated from potato. PCR amplicons of $750 \mathrm{bp}$ were amplified following previously published methods $(10,12,24)$ and

TABLE 1. (continued from preceding page)

\begin{tabular}{|c|c|c|c|c|c|}
\hline \multirow[b]{2}{*}{ Strain $^{\mathrm{a}}$} & \multirow[b]{2}{*}{$\mathrm{RUN}^{\mathrm{b}}$} & \multirow[b]{2}{*}{ Origin, host } & \multicolumn{2}{|c|}{ Phylotype } & \multirow[b]{2}{*}{ GenBank $^{\mathrm{e}}$} \\
\hline & & & $\mathrm{PCR}^{\mathrm{c}}$ & $e g l^{\mathrm{d}}$ & \\
\hline ACH92 & 44 & Australia, Ginger & $\mathrm{I}$ & I-16 & AF295254 \\
\hline P11 & 337 & China, peanut & I & $\mathrm{I}-17$ & FJ561068 \\
\hline GMI1000 & 54 & French Guiana, tomato & $\mathrm{I}$ & $\mathrm{I}-18$ & AF295251 \\
\hline JT519 & 471 & Reunion, Pelargonium sp. & I & $\mathrm{I}-31$ & GU295032 \\
\hline PSS219 & 257 & Taiwan, tomato & I & $\mathrm{I}-34$ & FJ561167 \\
\hline $\mathrm{O} 3$ & 339 & China, Olive tree & I & $\mathrm{I}-44$ & FJ561069 \\
\hline CIP365 & 47 & Philippines, potato & I & $\mathrm{I}-45$ & GQ907151 \\
\hline MAD17 & 320 & Madagascar, Pepper & $\mathrm{I}$ & $\mathrm{I}-46$ & GU295040 \\
\hline GMI8254 & 597 & Indonesia, tomato & $\mathrm{I}$ & $\mathrm{I}-47$ & GU295014 \\
\hline M2 & 343 & China, mulberry & I & $\mathrm{I}-48$ & FJ561067 \\
\hline UW181 & 454 & Venezuela, banana plantain & IIA-6 & IIA-6 & GU295053 \\
\hline ICMP7963 & 55 & Kenya, potato & II & IIA-7 & AF295263 \\
\hline K60 & 65 & USA, tomato & II & IIA-7 & AF295262 \\
\hline IBSBF1900 & 301 & Brazil, Musa sp. & II & IIA-24 & EF371839 \\
\hline CIP301 & 45 & Peru, potato & II & IIA-35 & GU295003 \\
\hline IBSBF1546 & 298 & Brazil, California fuchsia & II & IIA-35 & EF371877 \\
\hline CFBP2957 & 27 & Martinique, tomato & II & IIA-36 & AF295265 \\
\hline CFBP6779 & 288 & Martinique, Canna indica & II & IIA-38 & EF371872 \\
\hline CFBP2958 & 28 & Guadeloupe, tomato & II & IIA-39 & AF295266 \\
\hline CFBP2968 & 58 & Reunion, potato & II & IIA-39 & EF371806 \\
\hline UW469 & 109 & Brazil, potato & II & IIA-40 & DQ657612 \\
\hline CFBP7032 & 150 & Cameroon, tomato & II & IIA-41 & EF439726 \\
\hline T1-UY & 448 & Uruguay, tomato & II & IIA-50 & GU295049 \\
\hline CFBP7054 & 203 & Cameroon, tomato & II & IIA-52 & EF439725 \\
\hline IPO1609 & 1 & Netherlands, potato & II & IIB-1 & EF371814 \\
\hline UW551 & 449 & Kenya, Pelargonium sp. & II & IIB-1 & DQ657596 \\
\hline CFBP4611 & 894 & Colombia, potato & II & IIB-2 & GU294981 \\
\hline Molk2 & 74 & Philippines, Musa sp. & IIB-3 & IIB-3 & EF371841 \\
\hline CFBP6783 & 17 & Martinique, Heliconia sp. & IIB-4NPB & IIB-4 & EF371852 \\
\hline UW163 & 586 & Peru, banana plantain & IIB-4 & IIB-4 & GU295052 \\
\hline CIP10 & 40 & Peru, potato & II & IIB-25 & AF295260 \\
\hline CIP240 & 482 & Brazil, potato & II & IIB-26 & EF647739 \\
\hline IBSBF1712 & 299 & Brazil, Pelargonium sp. & II & IIB-27 & EF371833 \\
\hline NCPPB3987 & 79 & Brazil, potato & II & IIB-28 & AF295261 \\
\hline CFBP7014 & 297 & Trinidad, anthurium & II & IIB-51 & AF371831 \\
\hline JT525 & 60 & Reunion, Pelargonium sp. & III & III-19 & AF295272 \\
\hline MAD-29 & 332 & Madagascar, potato & III & III-19 & GU295041 \\
\hline CMR33 & 146 & Cameroon, tomato & III & III-20 & GU295007 \\
\hline $\mathrm{J} 25$ & 56 & Kenya, potato & III & III-20 & AF295279 \\
\hline NCPPB 1018 & 479 & Angola, potato & III & III-21 & AF295271 \\
\hline NCPPB332 & 1298 & Zimbabwe, potato & III & III-22 & AF295276 \\
\hline CFBP3059 & 39 & Burkina Faso, eggplant & III & III-23 & AF295270 \\
\hline CMR15 & 133 & Cameroon, tomato & III & III-29 & EF439743 \\
\hline CMR32 & 145 & Cameroon, huckleberry & III & III-29 & EF439749 \\
\hline DGBBC1227 & 364 & Guinea, potato & III & III-42 & GU295011 \\
\hline DGBBC1125 & 369 & Guinea, potato & III & III-43 & GU295008 \\
\hline DGBBC1138 & 362 & Guinea, potato & III & III-43 & GU295009 \\
\hline CMR66 & 166 & Cameroon, huckleberry & III & III-49 & EF439729 \\
\hline MAFF301558 & 71 & Japan, potato & IV & IV-8 & DQ011558 \\
\hline $\mathrm{R} 28$ & 89 & Indonesia, clove & IV & IV-9 & DQ011552 \\
\hline PSI7 & 83 & Indonesia, tomato & IV & IV -10 & EF371804 \\
\hline R229 & 62 & Indonesia, banana & IV & IV-10 & GU295045 \\
\hline $\mathrm{ACH} 732$ & 14 & Australia, tomato & IV & IV-11 & GQ907150 \\
\hline
\end{tabular}


sequenced by MACROGEN Korea (single-pass double-stranded analysis) using the Endo-F and the Endo-R primers. Sequences were manually edited, checked, and trimmed at the consensus start sequence 5'-ACGGCGAT-3' or 5'-ACGGCGGC-3' and the consensus end sequence 5'-CAGTGG-3'. Alignment was conducted under the ARB Package (23) on a Linux system and phylogenetic trees generated using the neighbor-joining (NJ) algorithm corrected using the Jukes-Cantor model. Tree topology was tested using bootstrap analysis of 2,000 resamplings of the data.

Pathogenicity testing. A subset of $R$. solanacearum strains ( $n=167$ ) for which egl gene sequences had previously been determined was tested for pathogenicity on different host plants. Cells were grown from a single $-80^{\circ} \mathrm{C}$ freeze-stored bead by placing the bead in $4.5 \mathrm{ml}$ of Luria-Burtani broth for $24 \mathrm{~h}$ at $28^{\circ} \mathrm{C}$ with $250 \mathrm{rpm}$ agitation for aeration; A 50- $\mu$ l volume was streaked on TZC-Kelman's medium plate. An isolated colony was selected to be restreaked and cultured for 24 to $36 \mathrm{~h}$ at $28^{\circ} \mathrm{C}$ on the same medium. A bacterial suspension in $10 \mathrm{mM}$ Tris, $\mathrm{pH} 7.1$ (7 to 9; Sigma-Aldrich, St. Louis) was made from the restreaked culture and adjusted to $10^{8} \mathrm{CFU} / \mathrm{ml}$ as determined by measuring the optical density at 0.1 at $650 \mathrm{~nm}$. Plants were inoculated at the threeleaf development stage by pouring $5 \mathrm{ml}$ of suspension on lateral roots that had been severed along one side using a scalpel. Negative control plants consisted of pouring $10 \mathrm{mM}$ Tris ( $\mathrm{pH}$ 7.1) onto severed roots. Pathogenicity was assessed on 10 plants per strainhost-experimental combination for tomato and eggplant accessions, whereas pathogenicity to banana was tested on 5 plants/ strain. Infected plants were placed in environmental growth chambers called Rotoplan (Strader, Pellouailles les Vignes, France). Rotoplans were agreed for different norms of security levels (NS) containment: nonexotic strains were incubated in growth chambers termed NS2 and quarantine exotic organisms in chambers termed NS3. Strains $(n=87)$ with a phylogenetic position previously recognized to be present on Reunion were considered to be without environmental risk and, therefore, were incubated under the standard security level NS2-Rotoplan. Strains exotic to Reunion $(n=80)$ were incubated in a high security quarantine level NS3-Rotoplan. Each strain-plant combination was separated from the other combinations using a watertight plastic bag to avoid cross-contaminations. Development of disease was visually assessed at 3-day intervals for wilting during 30 days. At the end of the assay, surviving asymptomatic plants were sampled by cutting a $2-\mathrm{cm}$ stem segment at collar level, and analyzed for latent infection by $R$. solanacearum by isolating the strain on a TZC-Kelman's medium plate. Special care was given to the sampling of infected banana for reculturing $R$. solanacearum targeting the corm leaf (CL) junction. A 2-cm segment of the CL section was sampled from all asymptomatic banana plants 3 weeks postinoculation; the first circular leaf was removed to avoid external contamination. Samples were crushed in $5 \mathrm{ml}$ of $10 \mathrm{mM}$ Tris, $\mathrm{pH} 7.1$, and left for $1 \mathrm{~h}$. A 50- $\mu$ l aliquot of each extract was plated onto Sequeira's and TZC-Kelman's medium and incubated at $28^{\circ} \mathrm{C}$ for $72 \mathrm{~h}$. A strain was said to be virulent to a particular plant species when showing the capacity to produce wilt symptoms and death on at least one single plant. Thus, pathogenicity of a strain was described by using two criteria: infections that resulted in plant death (wilt) and those that turned latent in a healthy plant carrier.

Pathogenicity assay of $\boldsymbol{R}$. solanacearum. Tests were performed on potato $\mathrm{cv}$. Bintje (Munterschen $\times$ Franschen) provided by the Fédération Nationale des Producteurs de Plants de Pommes de Terre (Rennes, France). Experimental conditions were two different regimes of night and day temperature conditions in the NS2-Rotoplan: temperate cold $\left(15\right.$ to $\left.24^{\circ} \mathrm{C}\right)$ and tropical hot $(24$ to $30^{\circ} \mathrm{C}$ ). Experiments in the NS3-Rotoplan were conducted in tropical hot temperature conditions. Strains $(n=156)$ were inoculated to potato plants to assess their phenotype (Tables 2 and 3 ).
Pathogenicity assay of brown rot ecotype strains. Comparative analysis of virulence and aggressiveness was based on strains $(n=14)$ (Table 4) described above as potato pathogenic: coldtolerant brown rot strains phylotype IIB-1, African brown rot strains phylotype III (24), and reference strains from phylotype I. Test were performed on tomato (Solanum lycopersicon) and on eggplant ( $S$. melongena) carrying different levels of resistance to BW: tomato L390 is highly susceptible to $R$. solanacearum (33) and, thus, strains that wilt this tomato were considered virulent on Solanaceae spp.; eggplant MM960 is moderately resistant to BW (3) and tomato Hawaii7996 is highly resistant $(5,33,35,39)$. These plants were grown in temperate cold and tropical hot temperature conditions in NS2-Rotoplan.

Pathogenicity assay of phylotype IIB. The phenotype of strains $(n=29)$ (Table 5) clustered into brown rot IIB-1 and IIB2; Moko disease IIA-6, IIB-3, and IIB-4; and blood disease bacterium IV-10 lineages were used to challenge on L390, MM960, Hawaii7996 ( $n=10$ plants), and Cavendish banana cv. Grande Naine ( $n=5$ plants) to established virulence pattern. Infected plants were placed in tropical hot temperature conditions in NS3-Rotoplan.

Statistics. Pathogenicity was estimated by using a colonization index (CI) (28) based on wilted plants and latent infections: $C I=$ $N_{W P}+\left(N_{S} \times R_{S}\right)$, where $N_{W P}$ is the percentage of wilted plants, $N_{S}$ is the percentage of symptomless plants, and $R_{S}$ is the percentage of those asymptomatic plants sampled from which $R$. solanacearum was recovered. Data from pathogenicity tests were analyzed with R software 2.9.2 (31) and its specific libraries cluster, $M A S S$, and $f p c$. The purpose of the following clustering method was to characterize the variability of phenotypes and, thus, identify clusters of strains that shared similar virulence or aggressiveness patterns. We used two methods to discriminate these clusters: (i) an agglomerative nesting which produced an ascendant hierarchical classification tree using Manhattan distance, where the validation of clusters is based on the internode distances, and (ii) a fuzzy analysis clustering which produced a partitioning, where the validation of the number of clusters was assessed by calculating the corrected Rand index between two clusterings with $k$ and $k+1$ clusters. A Rand index close to one validates the smallest clustering. Classification and partitioning were checked with biological data for supporting meaningful clusters.

\section{RESULTS}

Genetic diversity and phylogeny. Based on the PCR approach, strains of $R$. solanacearum used in this study $(n=210)$ (Table 1$)$ clustered into phylotype I $(n=2 ; 1 \%)$, phylotype II $(n=$ $197 ; 93.8 \%)$, phylotype III $(n=8 ; 3.8 \%)$, and phylotype IV $(n=$ $3 ; 1.4 \%)$. From this collection, 106 strains $(50.5 \%)$ originated or were intercepted in EuMr. Among the 15 different hosts of origin, potato and tomato were predominant, with $51 \%(n=107)$ and $22 \%(n=46)$ of the strains, respectively. The initial NJ tree computed from egl sequences was composed of the subset of 129 newly obtained sequences associated with 57 reference sequences representing all phylotypes; however, because all brown-rot strains in phylotype IIB-1 produced identical partial egl sequences, only 7 representatives were included to compute the phylogenetic tree (Fig. 1). Strains isolated from potato $(n=84)$ were distributed among all four phylotypes. A majority of strains from $\operatorname{EuMr}(n=71)$ were isolated from potato $(n=57)$. The $e g l$ sequences of 94 of 129 strains clustered into phylotype IIB-1, including 66 sequences from strains originating from EuMr and 75 sequences from strains isolated from potato. Only five strains originating from EuMr were not phylotype IIB-1: these strains clustered into phylotype IIA-7 with the tomato strain CFBP4822 from Finland, phylotype IIA-35 with the potato strain PD1100 from Egypt, phylotype IIB-3 with the potato strain UW28 from 
Cyprus (7), phylotype IIB-4NPB with the tomato strain LNPV24.25 from France, and phylotype IIB-25 with the potato strain UQRS607 from Iran.

Pathogenicity assay of $\boldsymbol{R}$. solanacearum. Strains of $R$. solanacearum inoculated to potato distributed into two clusters validated by the Rand index when considering separate temperature conditions. However, when considering pathogenicity scoring at both temperature conditions, the Rand index validated the distribution of strains into three clusters (Table 2). Cluster A strains $(n=28)$ were highly aggressive regardless of the incubation temperature and were all assigned into phylotype IIB-1 that belongs to cluster A ( $68 \%$ isolated from potato and $54 \%$ originating from EuMr). Cluster B strains $(n=24)$ were highly aggressive under tropical hot conditions but weakly aggressive (developing few or no wilted plants) under temperate cold temperatures. Strains in this group belonged to phylotypes I, IIA, IIB1, III, and IV (58\% isolated from potato and $27 \%$ originating from EuMr). Cluster $\mathrm{C}$ strains $(n=35)$ induced little or no wilt symptoms regardless of the incubation temperature. In total, $71 \%$ of strains from Cluster $\mathrm{C}$ were isolated from potato (57\% originating from EuMr), of which $69 \%$ were phylotype IIB-1 and other were representatives of phylotypes I, IIA, III, and IV. In this experiment, certain strains did not produce BW under either tropical hot or temperate cold conditions, although these strains were able to establish latent infections in potato $(n=6)$. These strains were representative of phylotypes IIB-1 $(n=5)$ and IIB-26 (CIP240).

Strains not pathogenic to potato $(n=20 ; C I=0)$ clustered into all phylotypes; namely, I-45, IIA-7, IIB-1 $(n=15)$, III-19, III-20, and IV-9. Strains not detected at Reunion (exotic) that were tested in NS3-Rotoplan $(n=69)$ under tropical hot temperature conditions distributed into three clusters validated by the Rand index (Table 3$)$. Cluster A strains $(n=32 ; C I \geq 90)$ were highly aggressive and distributed in phylotypes IIB-1, IIB-2, IIB-4, III (CMR20), and IV. Most of these strains were isolated from potato $(50 \%)$ and originated from EuMr (37.5\%). Cluster B strains were moderately aggressive $(n=20 ; 80 \geq C I \geq 50)$ and distributed in phylotypes IIA, IIB, III, and IV. Among these strains, $45 \%$ were

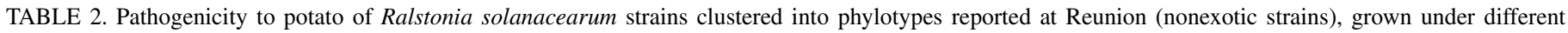
temperatures in security level NS2-Rotoplan ${ }^{\mathrm{a}}$

\begin{tabular}{|c|c|c|c|c|c|c|c|c|c|}
\hline \multirow[b]{2}{*}{ Strain } & \multirow[b]{2}{*}{ Origin, host } & \multirow[b]{2}{*}{ Phylotype } & \multicolumn{3}{|c|}{ Hot $^{b}$} & \multicolumn{3}{|c|}{ Cold $^{\mathrm{c}}$} & \multirow[b]{2}{*}{ Global $^{\mathrm{d}}$} \\
\hline & & & w & $\mathrm{CI}$ & Cluster & w & $\mathrm{CI}$ & Cluster & \\
\hline PSS4 & Taiwan, tomato & $\mathrm{I}-15$ & 9 & 90 & A & 3 & 30 & $\mathrm{C}$ & B \\
\hline GMI1000 & French Guiana, tomato & $\mathrm{I}-18$ & 8 & 80 & A & 0 & 30 & $\mathrm{C}$ & B \\
\hline CIP365 & Philippines, potato & $\mathrm{I}-45$ & 0 & 0 & $\mathrm{C}$ & 0 & 0 & $\mathrm{C}$ & $\mathrm{C}$ \\
\hline JS927 & Porto Rico, tomato & IIA-7 & 0 & 0 & $\mathrm{C}$ & 0 & 0 & $\mathrm{C}$ & $\mathrm{C}$ \\
\hline JS967 & Kenya, potato & IIA-7 & 2 & 20 & $\mathrm{C}$ & 0 & 0 & $\mathrm{C}$ & $\mathrm{C}$ \\
\hline CFBP4613 & Brazil, potato & IIA-28 & 4 & 40 & $\mathrm{C}$ & 0 & 0 & $\mathrm{C}$ & B \\
\hline CFBP3105 & Peru, potato & IIA-39 & 4 & 40 & $\mathrm{C}$ & 0 & 0 & $\mathrm{C}$ & B \\
\hline UW469 & Brazil, potato & IIA-40 & 5 & 50 & A & 0 & 0 & $\mathrm{C}$ & $\mathrm{B}$ \\
\hline CFBP1417 & Australia, potato & IIB-1 & 4 & 90 & A & 4 & 70 & A & A \\
\hline CFBP1810 & Haiti, potato & IIB-1 & 8 & 80 & A & 6 & 90 & A & A \\
\hline CFBP3579 & France, tomato & IIB-1 & 0 & 0 & $\mathrm{C}$ & 0 & 0 & $\mathrm{C}$ & $\mathrm{C}$ \\
\hline CFBP3583 & Egypt, potato & IIB-1 & 0 & 10 & $\mathrm{C}$ & 0 & 0 & $\mathrm{C}$ & $\mathrm{C}$ \\
\hline CFBP3784 & Portugal, potato & IIB-1 & 1 & 20 & $\mathrm{C}$ & 1 & 30 & $\mathrm{C}$ & $\mathrm{B}$ \\
\hline CFBP3785 & Portugal, potato & IIB-1 & 8 & 80 & A & 3 & 30 & $\mathrm{C}$ & B \\
\hline CFBP3857 & Netherlands, potato & IIB-1 & 2 & 20 & $\mathrm{C}$ & 0 & 0 & $\mathrm{C}$ & $\mathrm{C}$ \\
\hline CFBP3858 & Netherlands, potato & IIB-1 & 7 & 70 & A & 2 & 60 & A & B \\
\hline CFBP3863 & Morocco, potato & IIB-1 & 10 & 100 & A & 6 & 90 & A & A \\
\hline CFBP3865 & France, potato & IIB-1 & 0 & 0 & $\mathrm{C}$ & 0 & 0 & $\mathrm{C}$ & $\mathrm{C}$ \\
\hline CFBP3870 & South Africa, potato & IIB-1 & 3 & 50 & A & 2 & 30 & $\mathrm{C}$ & B \\
\hline CFBP3884 & Sweden, potato & IIB-1 & 0 & 0 & $\mathrm{C}$ & 0 & 0 & $\mathrm{C}$ & $\mathrm{C}$ \\
\hline CFBP3886 & Belgium, potato & IIB-1 & 4 & 40 & $\mathrm{C}$ & 1 & 10 & $\mathrm{C}$ & B \\
\hline CFBP3927 & Greece, potato & IIB-1 & 0 & 0 & $\mathrm{C}$ & 0 & 0 & $\mathrm{C}$ & $\mathrm{C}$ \\
\hline CFBP3937 & France, bittersweet & IIB-1 & 10 & 100 & A & 9 & 90 & A & A \\
\hline CFBP4577 & Egypt, potato & IIB-1 & 0 & 0 & $\mathrm{C}$ & 0 & 0 & $\mathrm{C}$ & $\mathrm{C}$ \\
\hline CFBP4578 & Egypt, tomato & IIB-1 & 5 & 60 & A & 2 & 30 & $\mathrm{C}$ & B \\
\hline CFBP4583 & Egypt, potato & IIB-1 & 10 & 100 & A & 10 & 100 & A & A \\
\hline CFBP4585 & Turkey, potato & IIB-1 & 10 & 100 & A & 9 & 100 & A & A \\
\hline CFBP4587 & United Kingdom, potato & IIB-1 & 10 & 100 & A & 10 & 100 & A & A \\
\hline CFBP4588 & United Kingdom, potato & IIB-1 & 4 & 60 & A & 3 & 70 & A & B \\
\hline CFBP4597 & United Kingdom, tomato & IIB-1 & 10 & 100 & A & 10 & 100 & A & A \\
\hline CFBP4598 & Cyprus, potato & IIB-1 & 1 & 10 & $\mathrm{C}$ & 0 & 0 & $\mathrm{C}$ & $\mathrm{C}$ \\
\hline CFBP4599 & Sweden, potato & IIB-1 & 8 & 80 & A & 8 & 80 & A & A \\
\hline CFBP4600 & Sweden, bittersweet & IIB-1 & 10 & 100 & A & 8 & 100 & A & A \\
\hline CFBP4604 & Netherlands, potato & IIB-1 & 10 & 100 & A & 9 & 100 & A & A \\
\hline CFBP4609 & Slovenia, potato & IIB-1 & 0 & 0 & $\mathrm{C}$ & 0 & 0 & $\mathrm{C}$ & $\mathrm{C}$ \\
\hline CFBP4634 & Spain, potato & IIB-1 & 2 & 20 & $\mathrm{C}$ & 2 & 20 & $\mathrm{C}$ & $\mathrm{C}$ \\
\hline CFBP4652 & France, tomato & IIB-1 & 7 & 70 & A & 3 & 50 & A & B \\
\hline CFBP4787 & Portugal, potato & IIB-1 & 7 & 70 & A & 8 & 100 & A & A \\
\hline & & & & & & & & (continues & next page) \\
\hline
\end{tabular}

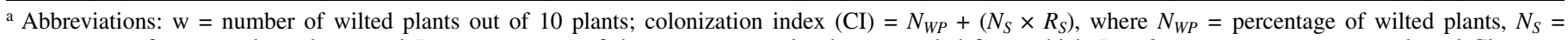
percentage of symptomless plants, and $R_{S}=$ percentage of those asymptomatic plants sampled from which $R$. solanacearum was recovered; and Cluster $=$ clusters based on CI computed after fuzzy analysis clustering. Rand index validated, in cold temperatures conditions, two clusters: $A(\mathrm{CI} \geq 50)$ and $B$ (CI $\leq 40)$ $(2$ vs. $3=0.634 ; 2$ vs. $4=0.878 ; 3$ vs. $4=0.878)$. Rand index validated, in hot tropical temperatures conditions, two clusters: $A$ (CI $\geq 50)$ and $B$ (CI $\leq 40)(2$ vs. $3=0.594 ; 2$ vs. $4=0.499 ; 3$ vs. $4=0.557)$.

${ }^{\mathrm{b}}$ Hot conditions referred to a night and day temperatures of 24 and $30^{\circ} \mathrm{C}$, respectively.

${ }^{c}$ Cold conditions referred to a night and day temperatures of 15 and $24^{\circ} \mathrm{C}$, respectively.

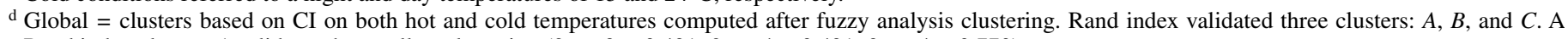
Rand index close to 1 validates the smallest clustering ( 2 vs. $3=0.491 ; 2$ vs. $4=0.491 ; 3$ vs. $4=0.770$ ). 
members of phylotype IIB-1, 75\% were isolated from potato, and $30 \%$ originated from EuMr. Cluster C strains ( $n=17$; $C I \leq 40)$ were weakly or not aggressive. This cluster encompassed a majority of phylotype IIB-1 (47\%) and strains in phylotype IIA and III. Most of these were strains isolated from potato (82\%) and originated from EuMr (76\%). Some strains in phylotypes IIA-7 (CFBP4822), IIB-1 ( $n=5$ ), IIB-3 (Molk2 and UW28), and III-21 were not able to develop wilt on potato under tropical hot experimental conditions but were able to established latent infections. Strains not pathogenic to potato $(C I=0)$ in tropical hot experimental conditions were composed of phylotype IIB-1 (potato strains CFBP3873 from Belgium and CFBP4607 from Portugal) and Moko disease-causing IIB-4 strain CFBP1184 from Honduras.

Pathogenicity assay of brown rot ecotype strains. In the NS2-Rotoplan, a subset of strains $(n=14)$ tested under tropical hot and temperate cold temperatures pathogenic to potato distributed into two clusters validated by the Rand index (Table 4). An identical clustering result was obtained whether temperatures were statistically analyzed separately or not. Strains in cluster A were all IIB-1 strains with high pathogenicity whatever the planttemperature combinations, except the South African potato strain CFBP3870 assigned in cluster B. Strains in cluster B were weakly pathogenic under temperate cold temperature conditions compared with the tropical hot temperature conditions.

Pathogenicity assay of phylotype IIB. Under tropical hot temperature conditions, strains tested in NS3-Rotoplan $(n=29)$ distributed in three different clusters that were validated by the Rand index (Table 5). Cluster A strains $(n=5)$ were highly virulent and phylogenetically clustered into phylotypes IIB-1 and IIB4NPB. Cluster B strains $(n=16)$ were able to wilt or to establish latent infections on all tested hosts; namely, GMI1000 (phylotype I-18) and Moko disease-causing strains from phylotypes IIA-6, IIB-3, and IIB-4. Cluster C strains $(n=8)$ caused no or little wilt or strains that were able to establish latent infections on susceptible tomato L390. Cluster C included strains from phylotypes IIA-6, IIB-2, IIB-3, and IIB-4 but also from phylotypes IIB-25 and IV-10. Two strains, CFBP1410 and CFBP1416, in phylotypes IIB-2 and IIB-3, respectively, were not able to develop wilt in tropical hot temperature conditions but did establish latent

TABLE 2. (continued from preceding page)

\begin{tabular}{|c|c|c|c|c|c|c|c|c|c|}
\hline \multirow[b]{2}{*}{ Strain } & \multirow[b]{2}{*}{ Origin, host } & \multirow[b]{2}{*}{ Phylotype } & \multicolumn{3}{|c|}{$\operatorname{Hot}^{\mathrm{b}}$} & \multicolumn{3}{|c|}{ Cold $^{\mathrm{c}}$} & \multirow[b]{2}{*}{ Global } \\
\hline & & & w & CI & Cluster & $\mathrm{w}$ & $\mathrm{CI}$ & Cluster & \\
\hline CFBP4788 & France, tomato & IIB-1 & 0 & 0 & $\mathrm{C}$ & 0 & 0 & $\mathrm{C}$ & $\mathrm{C}$ \\
\hline CFBP4801 & Reunion, tomato & IIB-1 & 9 & 90 & A & 8 & 80 & $\mathrm{~A}$ & A \\
\hline CFBP4808 & Israel, potato & IIB-1 & 0 & 0 & $\mathrm{C}$ & 0 & 0 & $\mathrm{C}$ & $\mathrm{C}$ \\
\hline CFBP4811 & France, Black nightshade & IIB-1 & 0 & 0 & $\mathrm{C}$ & 0 & 0 & $\mathrm{C}$ & $\mathrm{C}$ \\
\hline CFBP4812 & France, tomato & IIB-1 & 0 & 0 & $\mathrm{C}$ & 0 & 0 & $\mathrm{C}$ & $\mathrm{C}$ \\
\hline CFBP4821 & Sweden, potato & IIB-1 & 0 & 0 & $\mathrm{C}$ & 0 & 0 & $\mathrm{C}$ & $\mathrm{C}$ \\
\hline CFBP7101 & Spain, potato & IIB-1 & 0 & 0 & $\mathrm{C}$ & 0 & 20 & $\mathrm{C}$ & $\mathrm{C}$ \\
\hline CFBP7105 & Spain, water (river) & IIB-1 & 0 & 10 & $\mathrm{C}$ & 0 & 0 & $\mathrm{C}$ & $\mathrm{C}$ \\
\hline CFBP7108 & Kenya, Pelargonium sp. & IIB-1 & 4 & 60 & A & 0 & 70 & A & $\mathrm{B}$ \\
\hline CMR34 & Cameroon, tomato & IIB-1 & 8 & 90 & A & 9 & 100 & A & A \\
\hline CMR44 & Cameroon, potato & IIB-1 & 10 & 100 & A & 10 & 100 & A & A \\
\hline GRISP2335D & France, potato & IIB-1 & 10 & 100 & A & 9 & 100 & A & A \\
\hline GRISP2336B & France, tomato & IIB-1 & 9 & 90 & A & 9 & 100 & A & A \\
\hline IPO1609 & Netherlands, potato & IIB-1 & 1 & 10 & $\mathrm{C}$ & 0 & 0 & $\mathrm{C}$ & $\mathrm{C}$ \\
\hline JQ1006 & Reunion, potato & IIB-1 & 9 & 100 & A & 0 & 0 & $\mathrm{C}$ & $\mathrm{B}$ \\
\hline JQ1019 & Reunion, potato & IIB-1 & 5 & 60 & A & 4 & 50 & A & $\mathrm{B}$ \\
\hline JQ1023 & Reunion, tomato & IIB-1 & 3 & 40 & $\mathrm{C}$ & 1 & 30 & $\mathrm{C}$ & $\mathrm{B}$ \\
\hline JQ1051 & Reunion, tomato & IIB-1 & 0 & 0 & $\mathrm{C}$ & 0 & 0 & $\mathrm{C}$ & $\mathrm{C}$ \\
\hline JQ1073 & Reunion, tomato & IIB-1 & 10 & 100 & A & 9 & 100 & A & A \\
\hline JQ1107 & Reunion, potato & IIB-1 & 10 & 100 & A & 10 & 100 & A & A \\
\hline JQ1131 & Reunion, potato & IIB-1 & 8 & 90 & A & 7 & 80 & A & A \\
\hline JS925 & Sri Lanka, potato & IIB-1 & 6 & 60 & A & 10 & 100 & A & A \\
\hline JS926 & India, potato & IIB-1 & 0 & 20 & $\mathrm{C}$ & 0 & 0 & $\mathrm{C}$ & $\mathrm{C}$ \\
\hline JT511 & Reunion, potato & IIB-1 & 8 & 80 & A & 4 & 60 & A & B \\
\hline JT516 & Reunion, potato & IIB-1 & 1 & 30 & $\mathrm{C}$ & 0 & 40 & $\mathrm{C}$ & B \\
\hline JT646 & Sri Lanka, potato & IIB-1 & 0 & 0 & $\mathrm{C}$ & 0 & 0 & $\mathrm{C}$ & $\mathrm{C}$ \\
\hline LMG17139 & Cyprus, potato & IIB-1 & 10 & 100 & A & 8 & 100 & A & A \\
\hline LNPV19.66 & France, potato & IIB-1 & 10 & 100 & A & 7 & 80 & A & A \\
\hline LNPV23.54 & France, potato & IIB-1 & 0 & 0 & $\mathrm{C}$ & 0 & 0 & $\mathrm{C}$ & $\mathrm{C}$ \\
\hline LNPV27.43 & Guadeloupe, anthurium & IIB-1 & 0 & 0 & $\mathrm{C}$ & 0 & 0 & $\mathrm{C}$ & $\mathrm{C}$ \\
\hline LNPV28.23 & Reunion, potato & IIB-1 & 10 & 100 & A & 10 & 100 & A & A \\
\hline LNPV28.49 & France, bittersweet & IIB-1 & 10 & 100 & A & 8 & 90 & A & A \\
\hline PD441 & Sweden, potato & IIB-1 & 0 & 10 & $\mathrm{C}$ & 0 & 10 & $\mathrm{C}$ & $\mathrm{C}$ \\
\hline PSS525 & Taiwan, potato & IIB-1 & 8 & 100 & A & 10 & 100 & A & A \\
\hline RTG2 & Guinea, potato & IIB-1 & 9 & 100 & A & 6 & 100 & A & A \\
\hline UW551 & Kenya, Pelargonium sp. & IIB-1 & 10 & 100 & A & 7 & 90 & A & A \\
\hline CIP240 & Brazil, potato & IIB-26 & 0 & 20 & $\mathrm{C}$ & 0 & 0 & $\mathrm{C}$ & $\mathrm{C}$ \\
\hline JT525 & Reunion, Pelargonium sp. & III-19 & 0 & 0 & $\mathrm{C}$ & 0 & 0 & $\mathrm{C}$ & $\mathrm{C}$ \\
\hline MAD-29 & Madagascar, potato & III-19 & 2 & 20 & $\mathrm{C}$ & 0 & 0 & $\mathrm{C}$ & $\mathrm{C}$ \\
\hline CMR33 & Cameroon, tomato & III-20 & 3 & 30 & $\mathrm{C}$ & 0 & 20 & $\mathrm{C}$ & $\mathrm{B}$ \\
\hline $\mathrm{J} 25$ & Kenya, potato & III-20 & 0 & 0 & $\mathrm{C}$ & 0 & 0 & $\mathrm{C}$ & $\mathrm{C}$ \\
\hline CFBP3059 & Burkina Faso, eggplant & III-23 & 7 & 80 & A & 0 & 0 & $\mathrm{C}$ & B \\
\hline CMR32 & Cameroon, huckleberry & III-29 & 3 & 40 & $\mathrm{C}$ & 1 & 20 & $\mathrm{C}$ & $\mathrm{B}$ \\
\hline DGBBC1227 & Guinea, potato & III-42 & 10 & 100 & A & 0 & 10 & $\mathrm{C}$ & $\mathrm{B}$ \\
\hline DGBBC1125 & Guinea, potato & III-43 & 1 & 20 & $\mathrm{C}$ & 0 & 0 & $\mathrm{C}$ & $\mathrm{C}$ \\
\hline DGBBC1138 & Guinea, potato & III-43 & 7 & 70 & A & 0 & 20 & $\mathrm{C}$ & B \\
\hline CMR66 & Cameroon, huckleberry & III-49 & 6 & 60 & A & 0 & 0 & $\mathrm{C}$ & $\mathrm{B}$ \\
\hline MAFF301552 & Japan, tomato & IV-8 & 4 & 50 & A & 0 & 10 & $\mathrm{C}$ & $\mathrm{B}$ \\
\hline $\mathrm{R} 28$ & Indonesia, clove & IV-9 & 0 & 0 & $\mathrm{C}$ & 0 & 0 & $\mathrm{C}$ & $\mathrm{C}$ \\
\hline
\end{tabular}




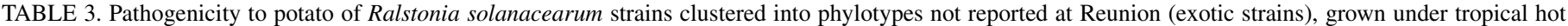
24 and $30^{\circ} \mathrm{C}$ (night and day, respectively) temperatures in security level NS3-Rotoplan

\begin{tabular}{|c|c|c|c|c|c|}
\hline Strain & Origin, host & Phylotype & $\mathrm{w}^{\mathrm{a}}$ & $\mathrm{CI}^{\mathrm{b}}$ & Cluster $^{\mathrm{c}}$ \\
\hline RUN394 & Grenada, banana Bluggoe & IIA-6 & 4 & 60 & $\mathrm{~B}$ \\
\hline CFBP4822 & Finland, tomato & IIA-7 & 0 & 10 & $\mathrm{C}$ \\
\hline ICMP7963 & Kenya, potato & IIA-7 & 5 & 70 & B \\
\hline CIP301 & Peru, potato & IIA-35 & 2 & 40 & $\mathrm{C}$ \\
\hline IBSBF1546 & Brazil, California fuchsia & IIA-35 & 9 & 100 & A \\
\hline PD1100 & Egypt, potato & IIA-35 & 3 & 40 & $\mathrm{C}$ \\
\hline CFBP2968 & Reunion, potato & IIA-39 & 7 & 80 & $\mathrm{~B}$ \\
\hline AP31H & Uruguay, potato & IIB-1 & 5 & 70 & $\mathrm{~B}$ \\
\hline CFBP3582 & Egypt, potato & IIB-1 & 0 & 50 & $\mathrm{~B}$ \\
\hline CFBP3872 & Belgium, potato & IIB-1 & 7 & 80 & $\mathrm{~B}$ \\
\hline CFBP3873 & Belgium, potato & IIB-1 & 0 & 0 & $\mathrm{C}$ \\
\hline CFBP3874 & Belgium, potato & IIB-1 & 10 & 100 & A \\
\hline CFBP3876 & Belgium, potato & IIB-1 & 1 & 20 & $\mathrm{C}$ \\
\hline CFBP3885 & Belgium, potato & IIB-1 & 0 & 20 & $\mathrm{C}$ \\
\hline CFBP3889 & Spain, potato & IIB-1 & 0 & 40 & $\mathrm{C}$ \\
\hline CFBP4580 & Egypt, potato & IIB-1 & 9 & 100 & A \\
\hline CFBP4581 & Egypt, potato & IIB-1 & 9 & 100 & A \\
\hline CFBP4582 & Egypt, potato & IIB-1 & 9 & 100 & A \\
\hline CFBP4584 & Egypt, potato & IIB-1 & 10 & 100 & A \\
\hline CFBP4601 & Belgium, potato & IIB-1 & 1 & 10 & $\mathrm{C}$ \\
\hline CFBP4605 & Netherlands, potato & IIB-1 & 9 & 90 & A \\
\hline CFBP4607 & Portugal, potato & IIB-1 & 0 & 0 & $\mathrm{C}$ \\
\hline CFBP4608 & Portugal, potato & IIB-1 & 0 & 30 & $\mathrm{C}$ \\
\hline CFBP4635 & Spain, potato & IIB-1 & 9 & 100 & $\mathrm{~A}$ \\
\hline CFBP4823 & Egypt, potato & IIB-1 & 4 & 60 & B \\
\hline CFBP7102 & Spain, potato & IIB-1 & 5 & 70 & $\mathrm{~B}$ \\
\hline CFBP7103 & Spain, potato & IIB-1 & 10 & 100 & A \\
\hline CFBP7104 & Spain, potato & IIB-1 & 8 & 80 & $\mathrm{~B}$ \\
\hline DGBBC1181 & Belgium, potato & IIB-1 & 4 & 50 & $\mathrm{~B}$ \\
\hline ETAC & Uruguay, potato & IIB-1 & 3 & 50 & B \\
\hline JS976 & Spain, potato & IIB-1 & 10 & 100 & A \\
\hline JS977 & Spain, potato & IIB-1 & 10 & 100 & A \\
\hline LMG2300 & Israel, potato & IIB-1 & 0 & 40 & $\mathrm{C}$ \\
\hline LMG9576 & Belgium, potato & IIB-1 & 8 & 90 & A \\
\hline PO41 & China, potato & IIB-1 & 4 & 90 & A \\
\hline $\mathrm{RM}$ & Uruguay, potato & IIB-1 & 10 & 100 & A \\
\hline UW394 & South Africa, potato & IIB-1 & 5 & 70 & B \\
\hline CFBP1410 & Colombia, banana plantain & IIB-2 & 9 & 100 & A \\
\hline CFBP3879 & Colombia, potato & IIB-2 & 4 & 70 & $\mathrm{~B}$ \\
\hline CFBP4611 & Colombia, potato & IIB-2 & 3 & 80 & B \\
\hline CIP418 & Indonesia, peanut & IIB-3 & 5 & 70 & $\mathrm{~B}$ \\
\hline Molk2 & Philippines, Musa sp. & IIB-3 & 0 & 40 & $\mathrm{C}$ \\
\hline UW28 & Cyprus, potato & IIB-3 & 0 & 40 & $\mathrm{C}$ \\
\hline CFBP1184 & Honduras, Musa sp. & IIB-4 & 0 & 0 & $\mathrm{C}$ \\
\hline LNPV31.10 & French Guiana, Musa sp. & IIB-4 & 9 & 100 & A \\
\hline LNPV32.36 & French Guiana, Musa sp. & IIB-4 & 7 & 90 & A \\
\hline LNPV32.37 & French Guiana, banana plantain & IIB-4 & 9 & 90 & A \\
\hline LNPV32.40 & French Guiana, Musa sp. & IIB-4 & 9 & 90 & A \\
\hline UW162 & Peru, banana plantain & IIB-4 & 5 & 50 & $\mathrm{~B}$ \\
\hline UW163 & Peru, banana plantain & IIB-4 & 7 & 90 & A \\
\hline UW170 & Colombia, Heliconia sp. & IIB-4 & 3 & 50 & $\mathrm{~B}$ \\
\hline CIP10 & Peru, potato & IIB-25 & 5 & 70 & $\mathrm{~B}$ \\
\hline UQRS607 & Iran, potato & IIB-25 & 2 & 20 & $\mathrm{C}$ \\
\hline NCPPB3987 & Brazil, potato & IIB-28 & 3 & 100 & A \\
\hline CFBP7014 & Trinidad, anthurium & IIB-51 & 9 & 100 & $\mathrm{~A}$ \\
\hline CFBP6778 & Martinique, tomato & IIB-4NPB & 10 & 100 & A \\
\hline CFBP6783 & Martinique, Heliconia sp. & IIB-4NPB & 9 & 90 & A \\
\hline CFBP6797 & Martinique, American nightshade & IIB-4NPB & 10 & 100 & A \\
\hline JY200 & Martinique, anthurium & IIB-4NPB & 10 & 100 & A \\
\hline LNPV24.25 & France, tomato & IIB-4NPB & 9 & 100 & A \\
\hline RUN432 & French Guiana, water (irrigation) & IIB-4NPB & 10 & 100 & $\mathrm{~A}$ \\
\hline NCPPB 1018 & Angola, potato & III-21 & 0 & 20 & $\mathrm{C}$ \\
\hline NCPPB332 & Zimbabwe, potato & III- 22 & 1 & 10 & $\mathrm{C}$ \\
\hline CMR15 & Cameroon, tomato & III-29 & 2 & 50 & $\mathrm{~B}$ \\
\hline CMR20 & Cameroon, tomato & III-29 & 3 & 100 & $\mathrm{~A}$ \\
\hline MAFF301558 & Japan, potato & IV-8 & 8 & 90 & A \\
\hline CFBP6727 & Indonesia, potato & IV -10 & 8 & 100 & A \\
\hline CFBP6728 & Indonesia, potato & IV -10 & 6 & 80 & B \\
\hline PSI7 & Indonesia, tomato & IV -10 & 10 & 100 & A \\
\hline
\end{tabular}

a Number of wilted plants out of 10 plants.

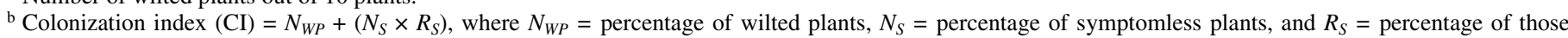
asymptomatic plants sampled from which $R$. solanacearum was recovered.

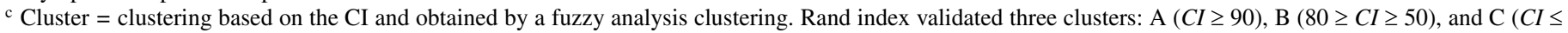
40). A Rand index close to 1 validates the smallest clustering ( 2 vs. $3=0.484 ; 2$ vs. $4=0.514 ; 3$ vs. $4=0.811$ ). 
infections in plants. Nonpathogenic strains to both tomato and eggplant $(n=4)$ in tropical hot experimental conditions were phylogenetically clustered into phylotypes IIA-6, IIB-3, and IV10. Strains pathogenic to banana were members of Moko phylotypes IIA-6, IIB-3, and IIB-4 and BDB phylotype IV-10 lineages. Strain CIP418 (phylotype IIB-3) isolated from peanut in Indonesia was virulent to banana and strain UW28 (phylotype IIB-3) isolated from potato in Indonesia Cyprus was not pathogenic on both host plants. All strains in Moko lineages established infection in banana plants (Table 5). Strains in phylotype IIB4NPB were not able to infect banana. From all non-Moko disease-causing strains tested in phylotype IIB, all were able to established latent infection in banana, with the exception of members of phylotypes IIB-25, IIB-26, IIB-28, and IIB-51. Strain GMI1000 showed no pathogenicity to banana.

\section{DISCUSSION}

In this study, we assessed genetic diversity, phylogeny, and pathogenicity traits challenging different Solanaceae spp. and banana with a set of strains of $R$. solanacearum from EuMr. These strains were mainly isolated from diseased potato plants from the field or quarantined by national plant health inspection services. Results showed a greater diversity than expected from the literature, especially regarding host range and pathotype of potato strains that clustered into phylotype II (10).

From the phylogenetic analysis of partial egl gene sequences and from the organismal phylogeny (16), it was evident that strains from $R$. solanacearum species complex phylotype II encompassed strains with both broad and narrow host ranges (11). Strains showing the narrowest host range belonged to ecotypes Moko (banana and heliconia) and brown rot (potato and tomato). These ecotypes have a much narrower definition reflected in their genetic diversity as well-described sequevars (IIB-1, IIB-2, IIA-6, IIA-24, IIB-3, and IIB-4), whereas broad host range strains are scattered among phylotype II. Based on the phylogenetic tree presented in this study, strains that cause BW on Solanaceae spp. distributed in all phylotypes (I, IIA, IIB, III, and IV), just as potato-pathogenic strains showed a wide range of aggressiveness and virulence (Table 6), mirroring a wide genetic basis for pathogenicity on these hosts. Most remarkable were virulence patterns of strains clustering into the Moko disease-causing phylotypes IIB-3 and IIB-4; although isolated from Musa spp. and pathogenic to banana, most strains were virulent to susceptible potato and tomato cultivars but not to eggplant, and phylotype IIB-4 strains were found to be virulent on resistant tomato Hawaii7996. The Moko disease-causing phylotype IIA-6, RUN394, was the only strain virulent to tomato, compared with the two other strains of the same phylotype in the time course of the experiment. Thus, in our experimental conditions, most banana strains inoculated to susceptible potato and tomato clustered into same pathogenicity cluster along with GMI1000, the model strain virulent on a wide range of Solanaceae spp. (32), including Molk2, the sequenced model genome of Moko disease-causing IIB-3 strains (15). As expected, the BDB strain R229 that clustered into the phylotype IV-10 was only pathogenic to banana.

It is noteworthy that experimental conditions applied in these experiments (injured roots and high concentration of inoculum) were in favor of BW development. Nevertheless, some Moko disease-causing strains were able to neither establish latent infection on Solanaceae spp. nor develop wilt. To our knowledge, no Moko disease-causing strains have ever been isolated from a wilted tomato or potato in the field, although it is now apparent that they were able to establish infections in these hosts. The three exceptions in our study were the phylotype IIB-2 strain CFBP1410 isolated from plantain (cooking banana) in Colombia, which established latent infection into banana; the phylotype IIB3 strain CIP418 isolated from peanut in Indonesia that wilted banana; and the phylotype IIB-3 strain UW28 isolated from potato that lacked pathogenicity on all plant species tested but still clustered in a Moko disease-causing phylotype.

As reported by Fegan and Prior (11), the polyphyletic nature of Moko disease-causing strains of $R$. solanacearum is evidenced by the observation that strains are found within phylotype IIA (sequevar 6) and phylotype IIB (sequevars 3 and 4). All Moko disease-causing strains in this study that were no more pathogenic to banana also lacked pathogenicity to tomato. This suggests a loss of major determinants in mechanisms governing patho-

TABLE 4. Pathogenicity to tomato and eggplant of nonexotic strains of Ralstonia solanacearum, grown under different temperatures in security level NS2Rotoplan ${ }^{\mathrm{a}}$

\begin{tabular}{|c|c|c|c|c|c|c|c|c|c|c|c|c|c|c|c|c|}
\hline \multirow[b]{3}{*}{ Strain } & \multirow[b]{3}{*}{ Phylotype } & \multicolumn{7}{|c|}{ Hot $^{b}$} & \multicolumn{7}{|c|}{ Cold $^{c}$} & \multirow[b]{3}{*}{ Glob $^{\mathrm{d}}$} \\
\hline & & \multicolumn{2}{|c|}{ L390 } & \multicolumn{2}{|c|}{ Hawaii7996 } & \multicolumn{2}{|c|}{ MM960 } & \multirow[b]{2}{*}{ Clu } & \multicolumn{2}{|c|}{ L390 } & \multicolumn{2}{|c|}{ Hawaii7996 } & \multicolumn{2}{|c|}{ MM960 } & \multirow[b]{2}{*}{ Clu } & \\
\hline & & $\mathrm{w}$ & CI & $\mathrm{w}$ & CI & $\mathrm{w}$ & CI & & w & CI & $\mathrm{w}$ & CI & $\mathrm{w}$ & CI & & \\
\hline PSS4 & $\mathrm{I}-15$ & $10 / 8$ & $100 / 90$ & $5 / 0$ & $50 / 10$ & $10 / 0$ & $100 / 80$ & $\mathrm{~A} / \mathrm{B}$ & $4 / 8$ & $50 / 80$ & $0 / 0$ & $0 / 0$ & $1 / 0$ & $20 / 30$ & $\mathrm{~B} / \mathrm{B}$ & $\mathrm{B} / \mathrm{B}$ \\
\hline GMI1000 & I-18 & $10 / 10$ & $100 / 100$ & $3 / 0$ & $50 / 20$ & $0 / 0$ & 0/0 & $\mathrm{B} / \mathrm{B}$ & $7 / 0$ & $70 / 10$ & $0 / 0$ & $20 / 0$ & $0 / 0$ & $0 / 10$ & $\mathrm{~B} / \mathrm{B}$ & $\mathrm{B} / \mathrm{B}$ \\
\hline CFBP3858 & IIB-1 & $10 / 10$ & $100 / 100$ & $8 / 8$ & $80 / 100$ & $6 / 3$ & $60 / 80$ & $\mathrm{~A} / \mathrm{A}$ & $9 / 6$ & $100 / 90$ & $8 / 0$ & $80 / 70$ & $3 / 0$ & $70 / 50$ & $\mathrm{~A} / \mathrm{A}$ & $\mathrm{A} / \mathrm{A}$ \\
\hline CFBP3870 & IIB-1 & $7 / 9$ & $70 / 100$ & $0 / 2$ & $0 / 100$ & $1 / 0$ & $10 / 60$ & $\mathrm{~B} / \mathrm{A}$ & $2 / 3$ & $20 / 50$ & $1 / 0$ & $10 / 10$ & $5 / 0$ & $50 / 20$ & $\mathrm{~B} / \mathrm{B}$ & $\mathrm{B} / \mathrm{B}$ \\
\hline CFBP4787 & IIB-1 & $10 / 10$ & $100 / 100$ & $8 / 7$ & $90 / 100$ & $8 / 1$ & $80 / 70$ & $\mathrm{~A} / \mathrm{A}$ & $9 / 10$ & $100 / 100$ & $10 / 3$ & $100 / 60$ & $9 / 0$ & $100 / 70$ & $\mathrm{~A} / \mathrm{A}$ & $\mathrm{A} / \mathrm{A}$ \\
\hline CMR34 & IIB-1 & $10 / 10$ & $100 / 100$ & $10 / 3$ & $100 / 90$ & $7 / 0$ & $70 / 70$ & $\mathrm{~A} / \mathrm{A}$ & $10 / 10$ & $100 / 100$ & $9 / 2$ & $100 / 70$ & $8 / 0$ & $80 / 50$ & $\mathrm{~A} / \mathrm{A}$ & $\mathrm{A} / \mathrm{A}$ \\
\hline JT516 & IIB-1 & $6 / 9$ & $80 / 100$ & $9 / 5$ & $90 / 80$ & $5 / 0$ & $60 / 50$ & $\mathrm{~A} / \mathrm{A}$ & $5 / 8$ & 60/90 & $8 / 0$ & $90 / 40$ & $6 / 0$ & $70 / 40$ & $\mathrm{~A} / \mathrm{A}$ & $\mathrm{A} / \mathrm{A}$ \\
\hline LNPV28.23 & IIB-1 & $10 / 10$ & $100 / 100$ & $10 / 4$ & $100 / 80$ & $9 / 0$ & $90 / 80$ & $\mathrm{~A} / \mathrm{A}$ & $10 / 10$ & $100 / 100$ & $9 / 5$ & $90 / 80$ & $9 / 0$ & $90 / 80$ & $\mathrm{~A} / \mathrm{A}$ & $\mathrm{A} / \mathrm{A}$ \\
\hline PSS525 & IIB-1 & $10 / 10$ & $100 / 100$ & $9 / 5$ & $100 / 100$ & $6 / 1$ & $70 / 80$ & $\mathrm{~A} / \mathrm{A}$ & $8 / 10$ & $90 / 100$ & $8 / 0$ & $90 / 80$ & $5 / 0$ & $80 / 60$ & $\mathrm{~A} / \mathrm{A}$ & $\mathrm{A} / \mathrm{A}$ \\
\hline UW551 & IIB-1 & $10 / 10$ & $100 / 100$ & $3 / 2$ & $100 / 100$ & $5 / 0$ & $70 / 90$ & $\mathrm{~A} / \mathrm{A}$ & $8 / 9$ & 90/90 & $8 / 5$ & $100 / 70$ & $7 / 0$ & $80 / 40$ & $\mathrm{~A} / \mathrm{A}$ & $\mathrm{A} / \mathrm{A}$ \\
\hline CMR33 & III-20 & $7 / 0$ & 70/10 & $0 / 0$ & 0/0 & $0 / 0$ & $0 / 10$ & $\mathrm{~B} / \mathrm{B}$ & $3 / 0$ & $30 / 20$ & $0 / 0$ & $10 / 10$ & $0 / 0$ & $0 / 10$ & $\mathrm{~B} / \mathrm{B}$ & $\mathrm{B} / \mathrm{B}$ \\
\hline CFBP3059 & III-23 & $10 / 7$ & $100 / 100$ & $10 / 0$ & $100 / 20$ & $0 / 0$ & $0 / 40$ & $\mathrm{~A} / \mathrm{B}$ & $8 / 0$ & $80 / 30$ & $0 / 0$ & $0 / 20$ & $1 / 0$ & $20 / 20$ & $\mathrm{~B} / \mathrm{B}$ & $\mathrm{B} / \mathrm{B}$ \\
\hline DGBBC 1138 & III-43 & $10 / 0$ & $100 / 30$ & $0 / 0$ & $0 / 10$ & $3 / 0$ & $30 / 30$ & $B / B$ & $1 / 1$ & $20 / 70$ & $0 / 0$ & $0 / 0$ & $1 / 0$ & $10 / 0$ & $\mathrm{~B} / \mathrm{B}$ & $\mathrm{B} / \mathrm{B}$ \\
\hline CMR66 & III-49 & $8 / 9$ & $80 / 100$ & $0 / 0$ & $10 / 20$ & $0 / 0$ & $0 / 10$ & $\mathrm{~B} / \mathrm{B}$ & $5 / 1$ & $50 / 40$ & $0 / 0$ & $10 / 0$ & $0 / 0$ & $0 / 10$ & $\mathrm{~B} / \mathrm{B}$ & $\mathrm{B} / \mathrm{B}$ \\
\hline
\end{tabular}

${ }^{a}$ Abbreviations: $\mathrm{w}=$ number of wilted plants out of 10 plants; colonization index $(\mathrm{CI})=N_{W P}+\left(N_{S} \times R_{S}\right)$, where $N_{W P}=$ percentage of wilted plants, $N_{S}=$ percentage of symptomless plants, and $R_{S}=$ percentage of those asymptomatic plants sampled from which $R$. solanacearum was recovered; and Clu $=$ clustering based on the CI and obtained by a fuzzy analysis clustering. Data organized as follows: replicate 1/replicate 2 .

${ }^{\mathrm{b}}$ Hot conditions referred to a night and day temperatures of 24 and $30^{\circ} \mathrm{C}$, respectively. Rand index validated, at hot tropical temperatures, two clusters: A and B (2 vs. $3=0.715 ; 2$ vs. $4=0.367 ; 3$ vs. $4=0.594$; second replicate: 2 vs. $3=0.822 ; 2$ vs. $4=0.455 ; 3$ vs. $4=0.594$ ).

${ }^{c}$ Cold conditions referred to a night and day temperature of 15 and $24^{\circ} \mathrm{C}$, respectively. Rand index validated, at cold temperatures, two clusters: A and B ( 2 vs. $3=$ $0.729 ; 2$ vs. $4=0.502 ; 3$ vs. $4=0.502$; second replicate: 2 vs. $3=0.775 ; 2$ vs. $4=0.518 ; 3$ vs. $4=0.518$ ).

${ }^{\mathrm{d}}$ Glob $=$ global clusters based on CI on both hot and cold temperatures computed after fuzzy analysis clustering. Rand index validated two clusters: A and B. A Rand index close to 1 validates the smallest clustering ( 2 vs. $3=0.729 ; 2$ vs. $4=0.495 ; 3$ vs. $4=0.728$; second replicate: 2 vs. $3=0.729 ; 2$ vs. $4=0.309 ; 3$ vs. $4=0.391$ ). Data organized as follow: replicate 1 replicate 2 . 
genicity for both the broad and narrow host range. Because we demonstrated that most strains pathogenic to banana were also pathogenic to potato and tomato, it is possible that other nonMoko disease-causing strains in each subcluster might have lost the ability to cause wilt on banana. Alternatively, horizontal gene transfer may have taken place between these two $R$. solanacearum lineages (IIA and IIB), allowing a non-banana-pathogenic organism to become a banana pathogen. In addition, some strains that were not isolated from any Musaceae maintained the ability to establish latent infections on banana, especially brown rot phylotype IIB-1 and IIB-2 strains and strain IBSBF1712 (IIB-27) isolated from pelargonium. Latent infections (i.e., the capacity of a strain to establish itself into the vascular tissues on a host [asymptomatic plant]) evidenced the conservation of an early step mechanism required for pathogenicity. When established as latent infections in a host, $R$. solanacearum strains may develop wilt or not (34), turning plant vasculature into an ecological niche of choice. On the one hand, from a phylogenetic point of view, closely related sequevars IIB-1, IIB-3, and IIB-4 address the question of host adaptation mechanisms which may have undergone a similar bottleneck evolution. On the other hand, from an epidemiological point of view and as regards actual cultural practice, IIB-1 brown rot strains that adapted to host cropped under a highland cold environment have almost no chance to meet with extensive tropical lowland crops, such as banana. In other words, a major finding of this work was to improve our understanding of the phenotype of $R$. solanacearum strains that are genetically and phylogenetically well characterized. A better understanding of pathogenicity traits, differentiating a nonhost versus susceptible or asymptomatic host, provides a relevant frame to accurately approach underlying mechanisms for host speciation at the "omics" era.

Pathogenicity assessment of brown rot strains was congruent with the literature (25) and highlighted the fact that only phylotype IIB-1 strains maintain a high level of virulence regardless of temperature tested. Other strains, including the most closely related phylotype, IIB-2, and the phylogenetically distant African brown rot strains from phylotype III (24), although isolated from highland areas, dramatically decreased in virulence under cold temperatures. This indicates that the virulence factors for cold tolerance need further studies. In addition, because all IIB-1 strains that lack pathogenicity to potato under cold temperature were also weakly or not pathogenic under a tropical hot environment, it is anticipated that pathogenicity may have been altered in these strains. As expected from the literature, cold-tolerant EuMr strains isolated from wilted potato, tomato, or bittersweet were clonal and phylogenetically clustered into phylotype IIB-1, equivalent to R3bv2. Nonetheless, according to pathogenicity tests on Solanaceae spp., phenotypes statistically differed into different pathogenicity clusters. Since their first introduction decades ago in Europe, brown rot strains may have undergone genomic adaptation in local populations and were selected according to their fitness.

In our study, 101 of 106 strains originating or being intercepted in EuMr clustered into the brown rot phylotype IIB-1. Within the phylotype IIB-4NPB, we identified strain LNPV24.25 isolated in 2001 from a wilted tomato produced in a greenhouse in the southeast of France (Laboratoire National de la Protection des Végétaux, Angers, personal communication), which indicates, to our knowledge, the first report of phylotype IIB-4NPB strain in

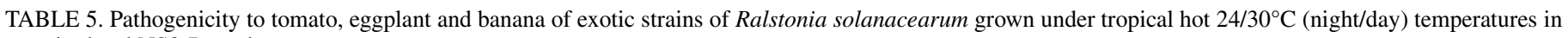
security level NS3-Rotoplan ${ }^{\mathrm{a}}$

\begin{tabular}{|c|c|c|c|c|c|c|c|c|c|c|c|}
\hline \multirow[b]{2}{*}{ Strain } & \multirow[b]{2}{*}{ Origin, host } & \multirow[b]{2}{*}{ Phylotype } & \multicolumn{2}{|c|}{$\mathrm{L} 390^{\mathrm{b}}$} & \multicolumn{2}{|c|}{ Hawaii7996 ${ }^{\text {b }}$} & \multicolumn{2}{|c|}{ MM960 } & \multirow[b]{2}{*}{ Cluster ${ }^{\mathrm{c}}$} & \multicolumn{2}{|c|}{ Banana $^{\mathrm{d}}$} \\
\hline & & & $\mathrm{w}$ & $\mathrm{CI}$ & $\mathrm{w}$ & $\mathrm{CI}$ & $\mathrm{w}$ & $\mathrm{CI}$ & & $\mathrm{w}$ & CI \\
\hline GMI1000 & French Guiana, tomato & $\mathrm{I}-18$ & $7(10)$ & 70 & $1(0)$ & 10 & $0(0)$ & 0 & $\mathrm{~B}$ & 0 & 0 \\
\hline GMI8044 & Grenada, banana & IIA-6 & $0(0)$ & 0 & $0(0)$ & 0 & $0(0)$ & 0 & $\mathrm{C}$ & 0 & 80 \\
\hline RUN394 & Grenada, banana Bluggoe & IIA-6 & $6(6)$ & 90 & $0(4)$ & 50 & $0(0)$ & 20 & $\mathrm{~B}$ & 5 & 100 \\
\hline UW181 & Venezuela, banana plantain & IIA-6 & $0(0)$ & 0 & $0(0)$ & 0 & $0(0)$ & 0 & $\mathrm{C}$ & 0 & 100 \\
\hline CFBP2957 & Martinique, tomato & IIA-36 & $6(9)$ & 80 & $0(2)$ & 20 & $4(0)$ & 60 & $\mathrm{~B}$ & 0 & 100 \\
\hline CMR34 & Cameroon, tomato & IIB-1 & $10(8)$ & 100 & $5(7)$ & 80 & $0(0)$ & 60 & $\mathrm{~A}$ & 0 & 80 \\
\hline LNPV28.23 & Reunion, potato & IIB-1 & $10(10)$ & 100 & $3(8)$ & 70 & $9(5)$ & 100 & A & 0 & 80 \\
\hline UW551 & Kenya, Pelargonium sp. & IIB-1 & $10(10)$ & 100 & $0(1)$ & 40 & $4(1)$ & 100 & A & 0 & 100 \\
\hline CFBP1410 & Colombia, banana plantain & IIB-2 & $0(0)$ & 30 & $0(0)$ & 20 & $0(0)$ & 50 & $\mathrm{~B}$ & 0 & 100 \\
\hline CFBP3879 & Colombia, potato & IIB-2 & $0(0)$ & 10 & $0(0)$ & 0 & $0(0)$ & 0 & $\mathrm{C}$ & 0 & 80 \\
\hline CFBP4611 & Colombia, potato & IIB-2 & $0(0)$ & 10 & $0(0)$ & 0 & $0(0)$ & 0 & $\mathrm{C}$ & 0 & 80 \\
\hline CFBP1416 & Costa Rica, banana plantain & IIB-3 & $0(0)$ & 60 & $0(0)$ & 20 & $0(0)$ & 0 & $\mathrm{~B}$ & 0 & 100 \\
\hline CIP417 & Philippines, banana & IIB-3 & $5(3)$ & 80 & $0(0)$ & 0 & $0(0)$ & 10 & $\mathrm{~B}$ & 3 & 100 \\
\hline CIP418 & Indonesia, peanut & IIB-3 & $2(9)$ & 30 & $0(0)$ & 10 & $0(0)$ & 0 & $\mathrm{C}$ & 5 & 100 \\
\hline Molk2 & Philippines, Musa sp. & IIB-3 & $6(8)$ & 90 & $0(0)$ & 0 & $0(0)$ & 10 & $\mathrm{~B}$ & 5 & 100 \\
\hline UW28 & Cyprus, potato & IIB-3 & $0(0)$ & 0 & $0(0)$ & 0 & $0(0)$ & 0 & $\mathrm{C}$ & 0 & 0 \\
\hline UW9 & Costa Rica, Heliconia sp. & IIB-3 & $0(3)$ & 50 & $0(0)$ & 10 & $0(0)$ & 10 & $\mathrm{~B}$ & 0 & 100 \\
\hline UW160 & Peru, banana plantain & IIB-4 & $9(10)$ & 90 & $4(3)$ & 60 & $0(0)$ & 0 & $\mathrm{~B}$ & 3 & 100 \\
\hline UW163 & Peru, banana plantain & IIB-4 & $9(9)$ & 90 & $4(1)$ & 60 & $0(0)$ & 10 & $\mathrm{~B}$ & 5 & 100 \\
\hline CIP10 & Peru, potato & IIB-25 & $2(2)$ & 40 & $0(0)$ & 0 & $0(0)$ & 0 & $\mathrm{C}$ & 0 & 0 \\
\hline IBSBF2001 & Brazil, tomato & IIB-25 & $7(9)$ & 80 & $0(5)$ & 30 & $0(3)$ & 0 & $\mathrm{~B}$ & 0 & 0 \\
\hline CIP240 & Brazil, potato & IIB-26 & $5(7)$ & 60 & $0(0)$ & 40 & $0(0)$ & 40 & $\mathrm{~B}$ & 0 & 0 \\
\hline IBSBF1712 & Brazil, Pelargonium sp. & IIB-27 & $10(4)$ & 100 & $0(0)$ & 20 & $0(0)$ & 0 & $\mathrm{~B}$ & 0 & 100 \\
\hline NCPPB3987 & Brazil, potato & IIB-28 & $3(3)$ & 60 & $0(0)$ & 0 & $0(0)$ & 10 & $\mathrm{~B}$ & 0 & 0 \\
\hline CFBP7014 & Trinidad, anthurium & IIB-51 & $6(5)$ & 100 & $1(0)$ & 20 & $0(0)$ & 40 & $\mathrm{~B}$ & 0 & 0 \\
\hline CFBP6783 & Martinique, Heliconia sp. & IIB-4NPB & $10(10)$ & 100 & $6(7)$ & 70 & $7(7)$ & 80 & $\mathrm{~A}$ & 0 & 0 \\
\hline IBSBF1503 & Brazil, cucumber & IIB-4NPB & $10(10)$ & 100 & $8(8)$ & 90 & $7(6)$ & 80 & A & 0 & 0 \\
\hline LNPV24.25 & France, tomato & IIB-4NPB & $10(9)$ & 100 & $5(9)$ & 50 & $2(2)$ & 20 & $\mathrm{~B}$ & 0 & 0 \\
\hline R229 & Indonesia, banana & IV-10 & $0(0)$ & 0 & $0(0)$ & 0 & $0(0)$ & 0 & $\mathrm{C}$ & 5 & 100 \\
\hline
\end{tabular}

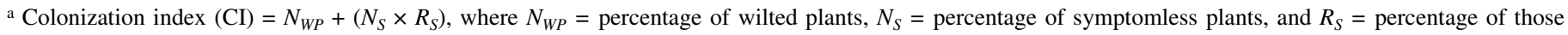
asymptomatic plants sampled from which $R$. solanacearum was recovered.

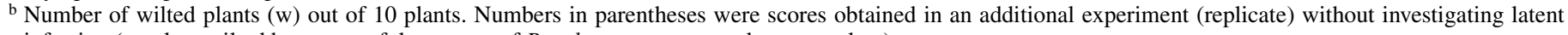
infection (no plant wilted but successful recovery of $R$. solanacearum on at least one plant).

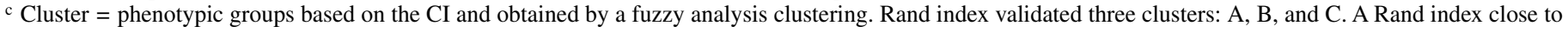
1 validates the smallest clustering ( 2 vs. $3=0.186 ; 2$ vs. $4=0.413 ; 3$ vs. $4=0.559$ ).

d Number of wilted plants (w) out of five plants. 
France; however, the infection was contained and no outbreak has been surveyed during the past decade. These strains assigned to phylotype IIB-4NPB, reported as emergent in Martinique by Wicker et al. in the French West Indies (40), are phylogenetically undistinguishable from the Moko disease-causing phylotype IIB-4 strains by partial egl gene analyses. Phylotypes IIB-4NPB strains were highly virulent and aggressive and overcame resistance on Solanaceae spp. They were statistically clustered in the same pathogenicity group as the brown rot phylotype IIB-1 strains and were not pathogenic to banana. The origin of this emerging pathogen remains unsolved and its pathogenicity toward cultivated
Musa spp. may have been lost or never acquired (41). In addition to LNPV24.25 (IIB-4NPB), four others strains from EuMr did not cluster into phylotype IIB-1: (i) potato strain UW28 (Cyprus) clustered into the Moko disease-causing phylotype IIB-3, equivalent to the multilocus genotype group 24 (MLG24), reported by Cook and Sequeira (7); (ii) tomato strain CFBP4822 (Finland) clustered into the American phylotype IIB-7; (iii) potato strain PD1100 (Finland) clustered into the phylotype IIA-35; and (iv) potato strain UQRS607 (Iran) that was previously reported as phylotype IIB-25 (26). These strains showed that, despite the great proportion of brown rot phylotype IIB-1 strains in EuMr

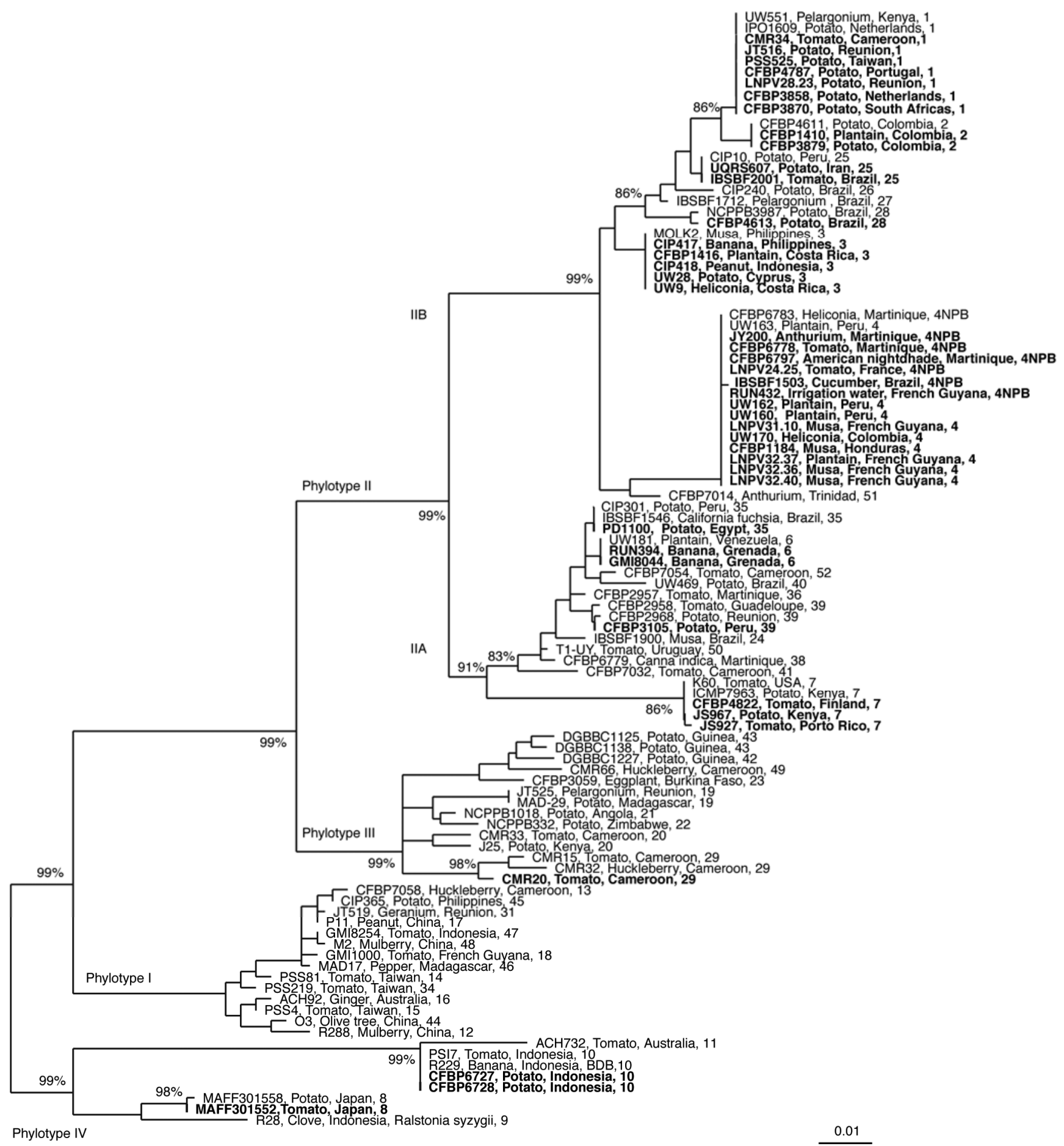

Fig. 1. Phylogenetic neighbor-joining tree based on partial sequences of the endoglucanase $(\mathrm{egl})$ gene sequences of a subset of strains from different bacterial collections or intercepted by national plant health inspection services (in bold), and Ralstonia solanacearum species complex reference strains. The number at each node is the bootstrap value (2,000 resamplings), and only significant bootstrap values $>80 \%$ are indicated. Scale bar represents 1 nucleotide substitution per 100. 
TABLE 6. Summary of the temperature-related virulence on potato of phylogenetic groups of Ralstonia solanacearum ${ }^{\text {a }}$

\begin{tabular}{lcc}
\hline Phylogenetic groups $^{\mathrm{b}}$ & Hot & Cold \\
\hline I & + & - \\
IIA & \pm & - \\
IIA Moko & + & nd \\
IIB-1 Brown rot & + & + \\
IIB Moko & + & nd \\
III & + & - \\
IV & + & - \\
IV (BDB) & - & nd \\
IV (RSY) & - & - \\
\hline
\end{tabular}

a Virulence observed on potato at tropical hot $\left(24\right.$ and $30^{\circ} \mathrm{C}$, night and day, respectively) and temperate cold $\left(15\right.$ and $24^{\circ} \mathrm{C}$, night and day, respectively) temperatures; $+=$ most of the strains tested $(\geq 50 \%)$ are virulent; $-=$ all strains tested are not virulent; $\pm=$ some of the strains tested are virulent; nd $=$ not done.

${ }^{\mathrm{b}} \mathrm{BDB}=$ blood disease bacterium and $\mathrm{RSY}=$ Ralstonia syzygii.

territory, other phylotypes may represent a potential threat to Solanaceae production. We also detected brown rot phylotype IIB-1 strains isolated from Anthurium and potato in Guadeloupe (French West Indies): LNPV27.43 and CFBP3880. respectively. Because R3bv2 was not reported from Guadeloupe (30), this suggests that these strains may be recently introduced.

In addition to deciphering pathogenicity traits, we described a set of three genetic resources that are useful in identifying pathogenicity clusters within $R$. solanacearum strains; namely, BWsusceptible tomato line L390, moderately resistant eggplant MM960, and highly resistant tomato Hawaii7996. Considering these three hosts, results showed that IIB-1 strains distributed into statistical clusters that gathered highly pathogenic and pathogenic phenotypes of strains according to their virulence and aggressiveness. This confirms and extends a previous report showing that no immunity or complete resistance was observed in any accessions in the Lycopersicon genus and relatives, facing IIB-1 strain JT516 (6).

These findings revealed that phylotype II strains share more virulence traits than expected from the literature, which is of major concern for investigating bacterial factors that control host or nonhost specificity, especially through post-genomic analysis of the $R$. solanacearum species complex.

\section{ACKNOWLEDGMENTS}

This work was funded by the Fédération Nationale des Producteurs de Plants de Pommes de Terre, Mission-DAR, Grant-7124 of the French Ministry of Food, Agriculture and Fisheries. The European Regional Development Fund (ERDF) of the European Union, Conseil Régional de La Réunion also provided financial support as part of Biorisk program developed at Centre de coopération Internationale en Recherche Agronomique pour le Développement. We thank M. Fegan, E. Wicker, J. C. De Cambiaire, and O. Pruvost for critical review before submission; F. Chiroleu for expertise in statistical analyses with R packages; J. M. Baptiste, J. J. Cheron, and S. Lebon for technical assistance; and institutions cited in the text for their courtesy in sharing strains of Ralstonia solanacearum.

\section{LITERATURE CITED}

1. Alfano, J. R. 2009. Roadmap for future research on plant pathogen effectors. Mol. Plant Pathol. 10:805-813.

2. Allen, C., Kelman, A., and French, E. R. 2001. Brown rot. In: Compendium of Potato Diseases. W. R. Stevenson, R. Loria, G. D. Franc, and D. P. Weingartner, eds. American Phytopathological Society, St. Paul, $\mathrm{MN}$.

3. Ano, G., Hebert, Y., Prior, P., and Messiaen, C. M. 1991. A new source of resistance to bacterial wilt of eggplants obtained from a cross: Solanum aethiopicum L. x Solanum melongena L. Agronomie 11:555-560.

4. Buddenhagen, I., Sequeira, L., and Kelman, A. 1962. Designation of races in Pseudomonas solanacearum. (Abstr.) Phytopathology 52:726.
5. Carmeille, A., Caranta, C., Dintinger, J., Prior, P., Luisetti, J., and Besse, P. 2006. Identification of QTLs for Ralstonia solanacearum race 3phylotype II resistance in tomato. Theor. Appl. Genet. 113:110-121.

6. Carmeille, A., Prior, P., Kodja, H., Chiroleu, F., Luisetti, J., and Besse, P. 2006. Evaluation of resistance to race 3, biovar 2 of Ralstonia solanacearum in tomato germplasm. J. Phytopathol. 154:398-402.

7. Cook, D., and Sequeira, L. 1994. Strain differentiation of Pseudomonas solanacearum by molecular genetic methods. In: Bacterial Wilt: The Disease and Its Causative Agent, Pseudomonas solanacearum. A. C. Hayward and G. L. Hartman, eds. CAB International, Wallingford, UK.

8. Eden-Green, S. J., and Adhi, E. M. 1986. Sumatra disease of cloves and Pseudomonas solanacearum. Bacteriol. Wilt Newsl. 1:2-3.

9. Elphinstone, J. G. 2005. The current bacterial wilt situation: A global overview. In: Bacterial Wilt Disease and the Ralstonia solanacearum Species Complex. C. Allen, P. Prior, and A. C. Hayward, eds. American Phytopathological Society Press, St. Paul, MN.

10. Fegan, M., and Prior, P. 2005. How complex is the "Ralstonia solanacearum species complex". In: Bacterial Wilt Disease and the Ralstonia solanacearum Species Complex. C. Allen, P. Prior, and A. C. Hayward, eds. American Phytopathological Society Press, St. Paul, MN.

11. Fegan, M., and Prior, P. 2006. Diverse members of the Ralstonia solanacearum species complex cause bacterial wilts of banana. Australas. Plant Pathol. 35:93-101.

12. Fegan, M., Taghavi, M., Sly, L. I., and Hayward. A. C. 1998. Phylogeny, diversity and molecular diagnostics of Ralstonia solanacearum. In: Bacterial Wilt Disease: Molecular and Ecological Aspects. P. Prior, C. Allen, and J. Elphinstone, eds. INRA Editions, Paris.

13. Granada, G., and Sequeira, L. 1983. A new selective medium for Pseudomonas solanacearum. Plant Dis. 67:1084-1088.

14. Grousset, F., Roy, A. S., and Smith, I. M. 1998. Situation of Ralstonia solanacearum in the EPPO region in 1997. EPPO Bull. 1-2:53-63.

15. Guidot, A., Elbaz, M., Carrere, S., Siri, M. I., Pianzzola, M. J., Prior, P., and Boucher, C. 2009. Specific genes from the potato brown rot strains of Ralstonia solanacearum and their potential use for strain detection. Phytopathology 99:1105-1112.

16. Guidot, A., Prior, P., Schoenfeld, J., Carrere, S., Genin, S., and Boucher, C. 2007. Genomic structure and phylogeny of the plant pathogen Ralstonia solanacearum inferred from gene distribution analysis. J. Bacteriol. 189:377-387.

17. Hayward, A. C. 1991. Biology and epidemiology of bacterial wilt caused by Pseudomonas solanacearum. Annu. Rev. Phytopathol. 29:67-87.

18. Hayward, A. C. 1994. The hosts of Pseudomonas solanacearum. In: Bacterial Wilt: The Disease and Its Causative Agent, Pseudomonas solanacearum. A. C. Hayward and G. L. Hartman, eds. CAB International, Wallingford, UK.

19. Hayward, A. C. 2000. Ralstonia solanacearum. In: Encyclopedia of Microbiology. J. Lederberg, ed. Academic Press, San Diego, CA.

20. Janse, J. D. 1996. Potato brown rot in western Europe-history, present occurrence and some remarks on possible origin. EPPO Bull. 26:17.

21. Kelman, A. 1954. The relationship of pathogenicity in Pseudomonas solanacearum to colony appearance on a tetrazolium medium. Phytopathology 44:693-695

22. Lambert, C. D. 2002. Agricultural Bioterrorism Protection Act of 2002: Possession, Use, and Transfer of Biological; Agents and Toxins; Interim and Final Rule. Fed. Regist. 67:76907-76938.

23. Ludwig, W., Strunk, O., Westram, R., Richter, L., Meier, H., Yadhukumar, Buchner, A., Lai, T., Steppi, S., Jobb, G., Forster, W., Brettske, I., Gerber, S.. Ginhart, A. W., Gross, O., Grumann, S., Hermann, S., Jost, R., Konig, A., Liss, T., Lussmann, R., May, M., Nonhoff, B., Reichel, B., Strehlow, R., Stamatakis, A., Stuckmann, N., Vilbig, A., Lenke, M., Ludwig, T., Bode, A., and Schleifer, K. H. 2004. ARB: A software environment for sequence data. Nucleic Acids Res. 32:1363-1371.

24. Mahbou Somo Toukam, G., Cellier, G., Wicker, E., Guilbaud, C., Kahane, R., Allen, C., and Prior, P. 2009. Broad diversity of Ralstonia solanacearum strains in Cameroon. Plant Dis. 93:1123-1130.

25. Milling, A., Meng, F., Denny, T. P., and Allen, C. 2009. Interactions with hosts at cool temperatures, not cold tolerance, explain the unique epidemiology of Ralstonia solanacearum race 3 biovar 2. Phytopathology 99:1127-1134

26. Nouri, S., Bahar, M., and Fegan, M. 2009. Diversity of Ralstonia solanacearum causing potato bacterial wilt in Iran and the first record of phylotype II/biovar 2T strains outside South America. Plant Pathol. 243249.

27. Poussier, S., Vandewalle, P., and Luisetti, J. 1999. Genetic diversity of African and worldwide strains of Ralstonia solanacearum as determined by PCR-restriction fragment length polymorphism analysis of the hrp gene region. Appl. Environ. Microbiol. 65:2184-2194.

28. Prior, P., Bart, S., Leclercq, S., Darrasse, A., and Anais, G. 1996. Resistance to bacterial wilt in tomato as discerned by spread of Pseudomonas (Burholderia) solanacearum in the stem tissues. Plant Pathol. 
45:720-726.

29. Prior, P., and Fegan, M. 2005. Recent developments in the phylogeny and classification of Ralstonia solanacearum. Acta Hortic. 695:127-136.

30. Prior, P., and Steva, H. 1990. Characteristics of strains of Pseudomonas solanacearum from the French West Indies. Plant Dis. 74:13-17.

31. R: A Language and Environment for Statistical Computing. R Foundation for Statistical Computing, Vienna.

32. Salanoubat, M., Genin, S., Artiguenave, F., Gouzy, J., Mangenot, S., Arlat, M., Billault, A., Brottier, P., Camus, J. C., Cattolico, L., Chandler, M., Choisne, N., Claudel-Renard, C., Cunnac, S., Demange, N., Gaspin, C., Lavie, M., Moisan, A., Robert, C., Saurin, W., Schiex, T., Siguier, P., Thebault, P., Whalen, M., Wincker, P., Levy, M., Weissenbach, J., and Boucher, C. A. 2002. Genome sequence of the plant pathogen Ralstonia solanacearum. Nature 415:497-502.

33. Scott, J. W., Wang, J. F., and Hanson, P. M. 2005. Breeding tomatoes for resistance to bacterial wilt, a global view. In: Proc. First Int. Symp. Tomato Dis. M. T. Momol, P. Ji, and J. B. Jones, eds. International Society Horticultural Science, Brugge, Belgium.

34. Swanson, J. K., Yao, J., Tans-Kersten, J., and Allen, C. 2005. Behavior of Ralstonia solanacearum race 3 biovar 2 during latent and active infection of geranium. Phytopathology 95:136-143.

35. Thoquet, P., Oliver, J., Sperisen, C., Rogowsky, P., Prior, P., Anaïs, G., Mangin, B., Bazin, B., Nazer, R., and Grimsley, N. 1996. Polygenic resistance of tomato plants to bacterial wilt in the French West Indies. Mol. Plant-Microbe Interact. 9:837-842.

36. Timms-Wilson, T. M., Bryant, K., and Bailey, M. J. 2001. Strain characterization and $16 \mathrm{~S}-23 \mathrm{~S}$ probe development for differentiating geographically dispersed isolates of the phytopathogen Ralstonia solanacearum. Environ. Microbiol. 3:785-797.

37. Trigalet, A., Trigalet-Demery, D., and Feuillade, R. 1998. Aggressiveness of French isolates of Ralstonia solanacearum and their potential use in biocontrol. EPPO Bull. 28:101-107.

38. van der Wolf, J. M., Bonants, P. J. M., Smith, J. J., Hagenaar, M., Nijhuis, E., van Beckhoven, J. R. C. M., Saddler, G. S., Trigalet, A., and Feuillade, R. 1998. Genetic diversity of Ralstonia solanacearum race 3 in Western Europe determined by AFLP, RC-PFGE and Rep-PCR. In: Bacterial Wilt Disease: Molecular and Ecological Aspects. P. Prior, C. Allen, and J. Elphinstone, eds. Springer Verlag, Berlin.

39. Wang, J.-F., Olivier, J., Thoquet, P., Mangin, B., Sauviac, L., and Grimsley, N. H. 2000. Resistance of tomato line Hawaii7996 to Ralstonia solanacearum Pss4 in Taiwan is controlled mainly by a major strainspecific locus. Mol. Plant-Microbe Interact. 13:6-13.

40. Wicker, E., Grassart, L., Coranson-Beaudu, R., Mian, D., Guilbaud, C., Fegan, M., and Prior, P. 2007. Ralstonia solanacearum strains from Martinique (French West Indies) exhibiting a new pathogenic potential. Appl. Environ. Microbiol. 73:6790-6801.

41. Wicker, E., Grassart, L., Coranson-Beaudu, R., Mian, D., and Prior, P. 2009. Epidemiological evidence for the emergence of a new pathogenic variant of Ralstonia solanacearum in Martinique (French West Indies). Plant Pathol. 58:853-851.

42. Yabuuchi, E., Kosako, Y., Yano, I., Hotta, H., and Nishiuchi, Y. 1995. Transfer of two Burkholderia and an Alcaligenes species to Ralstonia gen. Nov: proposal of Ralstonia pickettii (Ralston, Palleroni and Doudoroff 1973) comb. Nov., Ralstonia solanacearum (Smith 1896) comb. Nov. and Ralstonia eutropha (Davis 1969) comb. Nov. Microbiol. Immunol. 39:897-904. 